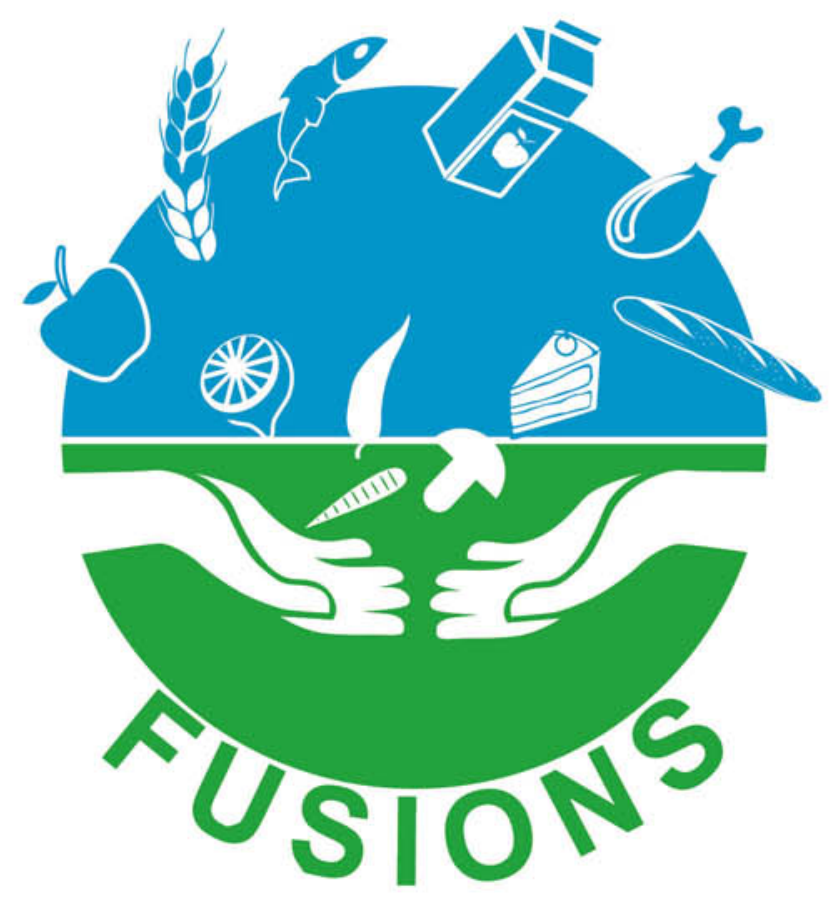

\title{
Scenario analysis on current trends of food waste generation
}

Date: 29.09 .2016 


\section{Colophon}

Title

Main authors

Acknowledgments

Disclaimer

Keywords

Project leader

Client
Scenario analysis on current trends of food waste generation

Lusine Aramyan, Wageningen Economic Research, The Netherlands

Natalia Valeeva, Wageningen Economic Research, The Netherlands

Silvia Gaiani, Unibo - University of Bologna, Italy

Alessandro Politano, Unibo - University of Bologna, Italy

Manuela Gheoldus - Deloitte Sustainability, France

Stephanie Burgos - Deloitte Sustainability, France

David Rogers, WRAP, UK

Silvia Scherhaufer, BOKU, Austria

Matteo Vittuari, Unibo - University of Bologna, Italy

Katherine Salès - Deloitte Sustainability, France

All experts who take part in this study - See the list of experts at the end of the document.

The information and views set out in this report represent the interpretation of the authors and do not necessarily reflect the opinion of the experts engaged in the interviews.

Policy instruments, scenario analysis, social trends

Toine Timmermans and Hilke Bos-Brouwers; Wageningen Food \& Biobased (FUSIONS Project Coordinators)

The European Commission, FP7-Coordination and Support Action (Contract No 311972)

\section{WP/Deliverable: WP3, part of Deliverable D3.5 (a)}

All rights reserved. No part of this publication may be reproduced, stored in a retrieval system of any nature, or transmitted, in any form or by any means, electronic, mechanical, photocopying, recording or otherwise, without the prior permission of the publisher. The publisher does not accept any liability for inaccuracies in this report.

Wageningen, September 2016 


\section{Index}

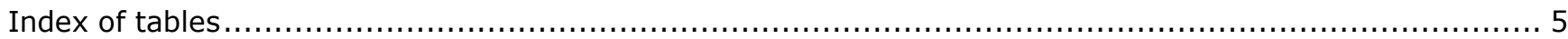

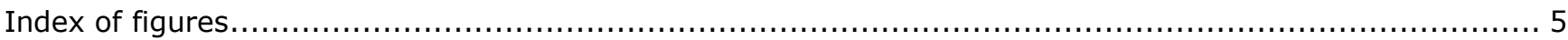

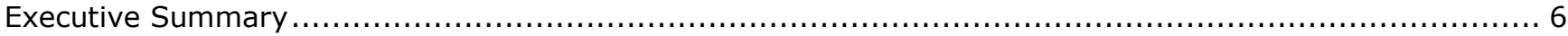

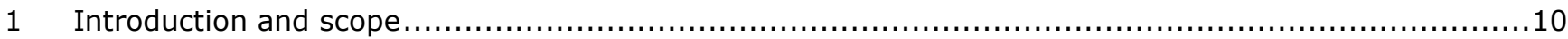

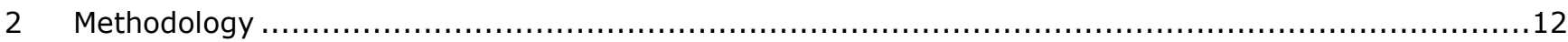

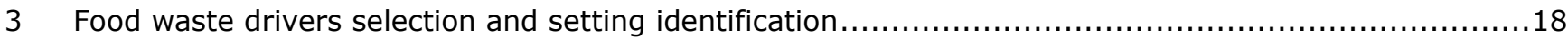

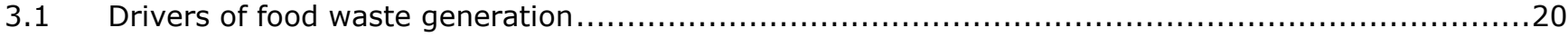

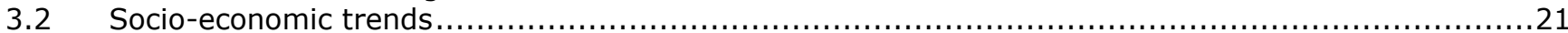

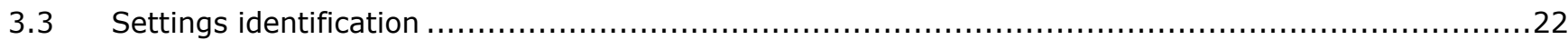

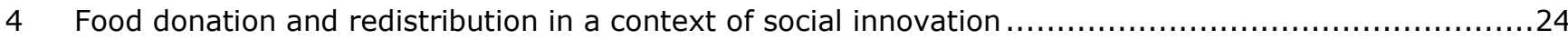

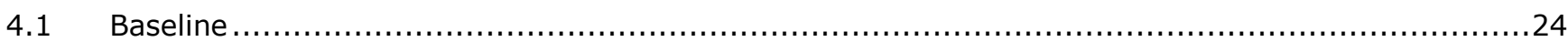

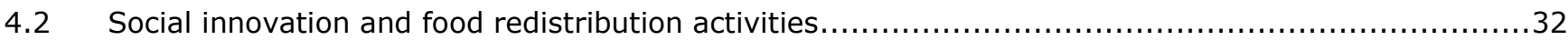

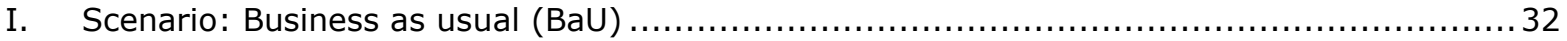

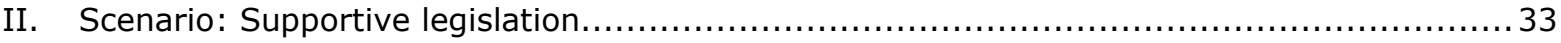

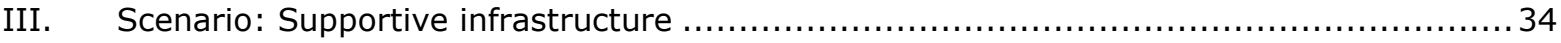

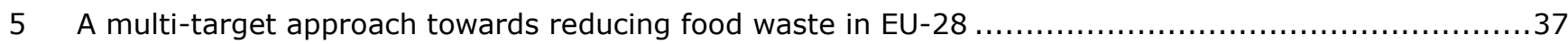

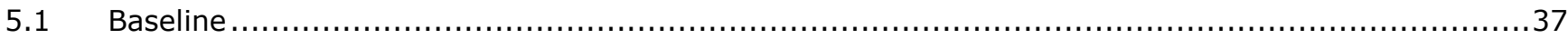

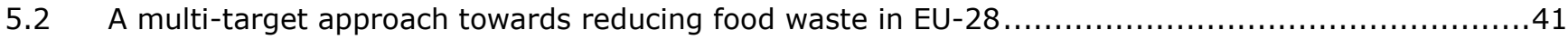

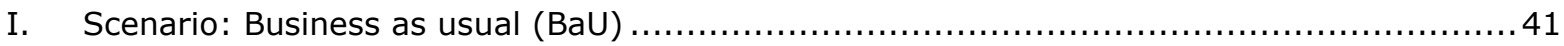

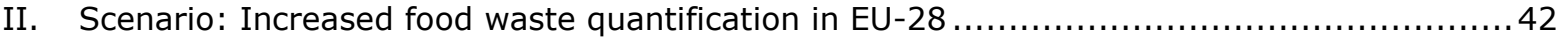

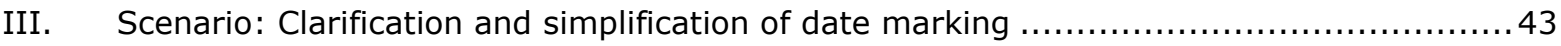

IV. Scenario: Guidance on valorisation solutions.................................................. 44

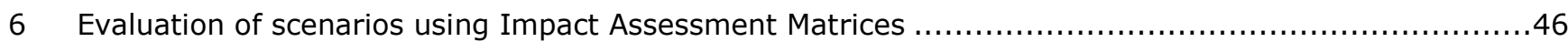

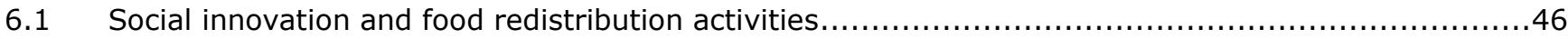

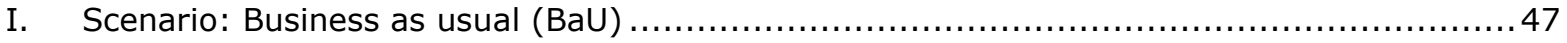

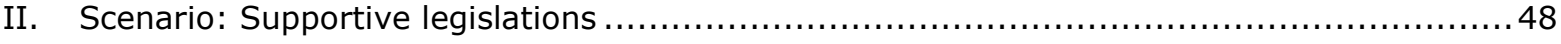

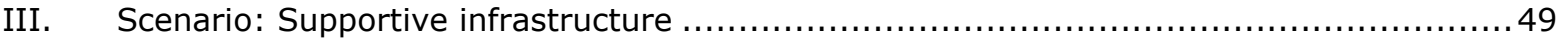

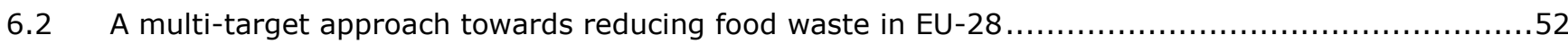




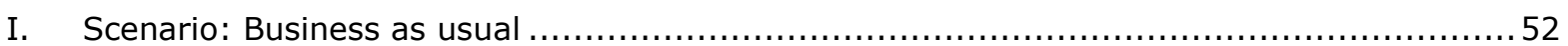

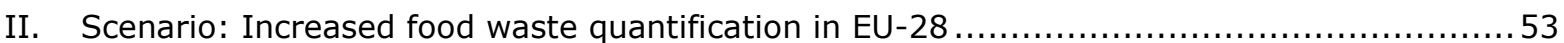

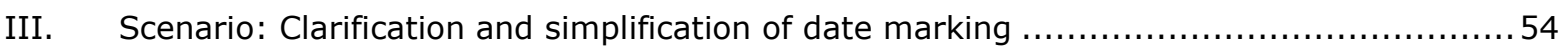

IV. Scenario: Guidance on valorisation solutions............................................ 55

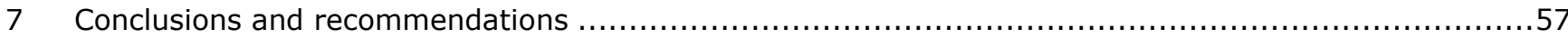

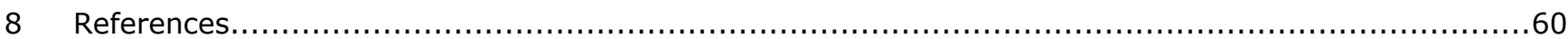

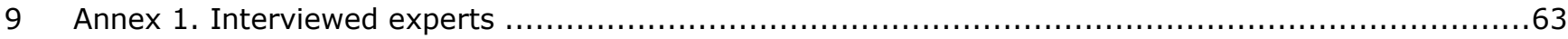




\section{Index of tables}

Table 2.1 Methodological steps and main sources of evidence .......................................... 13

Table 2.2 Food waste drivers and related policy measures .............................................. 13

Table 2.3 Settings, scenarios and sources of evidence..................................................... 15

Table 2.4 Impact Assessment Matrix_Setting A ........................................................ 16

Table 2.5 Scoring system for the impact assessment of scenarios for both settings....................... 16

Table 2.6 Impact Assessment Matrix_Setting B ...................................................... 16

Table 4.1 Summary: food donation and redistribution ................................................. 35

Table 5.1 Summary: Multi-target approach towards reducing food waste in EU-28 ..................... 45

Table 6.1 Impact assessment Setting A............................................................. 46

Table 6.2 Scoring system for the impact assessment of scenarios....................................... 47

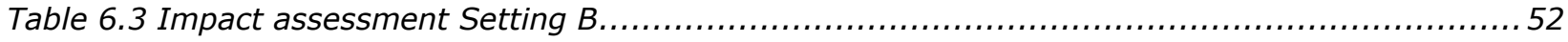

\section{Index of figures}

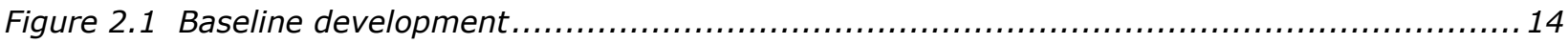

Figure 3.1 Policy instruments according to different approaches ......................................... 19

Figure 4.1 System map: food donation and redistribution ................................................. 31

Figure 5.1 System map: multi-target approach towards reducing food waste in EU-28.................40

Figure 6.1 Individual Experts' Impact Assessment of three scenarios .................................... 50

Figure 6.2 Impact assessment based on experts' interviews \& FUSIONS EPM Consultations.............. 51 


\section{Executive Summary}

The study "Scenario analysis on current trends of food waste generation" has been developed within the Work Package 3 "Recommendations for a Common EU Policy" of the FP7 project FUSIONS - Food Use for Social Innovation by Optimising Waste Prevention Strategies. The aim of the work is to identify and analyse - through a comparative assessment of selected scenarios - targeted policy interventions addressing specific food waste drivers to evaluate food waste reduction opportunities in Europe in light of the $50 \%$ food waste reduction by 2030 at retail and consumer level as foreseen by the Sustainable Development Goals (SDG).

To ensure the consistency of this exercise, prevent broader generalization and limit the number of potential variables influencing the scenarios, two specific settings were identified:

Setting A. Food donation and redistribution in a context of social innovation; and

Setting B. Multi-target approach towards reducing food waste.

The settings have been chosen through a number of individual experts interviews, consultations organized within the different FUSIONS RPMs - Regional Platform meetings ${ }^{1}$ and on the basis of the knowledge created in previous (and related) FUSIONS activities as:

- D1.5: Drivers of current food waste generation, threats of future increase and opportunities for reduction;

- D1.6: Criteria for and baseline assessment of environmental and socio-economic impacts of food waste D1.8: Estimates of European food waste levels;

- D3.2: Review of EU legislation and policies with implications on food waste;

- D3.1a: FUSIONS Country Reports of EU Member States legislation and policies addressing food waste (web consultation);

- D3.3a: Market-based instruments and other socio-economic incentives enhancing food waste prevention and reduction;

- D3.3b: Policy options to stimulate social innovation initiatives addressing food waste prevention and reduction.

For each of two settings a preliminary identification of the relevant food waste drivers was carried out. The identification of the drivers represented the theoretical background to develop the different scenarios and determine their boundaries.

More specifically the study was developed according to the following five methodological steps:

1. food waste drivers selection and setting's boundaries identification;

2. system map development;

3. baseline development;

4. scenario building (narrative);

5. analysis of scenarios.

The comparative assessment has been performed among the scenarios of the same setting and not between the two settings. The two settings use the same Qualitative Impact Assessment Matrix adapted from BIOIS (2010) - that takes into account experts' perceptions on the implications of different scenarios on a number of specific areas. Perceptions are evaluated through a scoring system. Although the settings share the same Qualitative Impact Assessment Matrix, the data sources are different: the setting Food donation and redistribution in a context of social innovation is based on information retrieved through the consultation sessions at FUSIONS RPMs and EPMs (therefore with a focus group approach) and individual experts interviews; the setting Multi-target approach towards reducing food waste is based on information retrieved with a set of individual experts interviews.

\footnotetext{
${ }^{1}$ FUSIONS Platform Meetings: http://www.eu-fusions.org/index.php/events/platform-meetings.
} 
Setting A: Food donation and redistribution in a context of social innovation

Within the setting Food donation and redistribution activities in a context of Social Innovation identified drivers include:

1. lack of economic incentives to donate;

2. food safety, liability issues and labelling for food durability;

3. redistribution capacity and costs.

On the basis of these drivers three scenarios were identified and developed (see Table ES1).

Table ES1. Scenarios for Food donation and redistribution activities in a context of social innovation

\begin{tabular}{|l|l|}
\hline Scenarios & $\begin{array}{l}\text { Summary of hypotheses - Food donation/redistribution in a context of } \\
\text { social innovation }\end{array}$ \\
\hline Business as usual & $\begin{array}{l}\text { No significant changes in the food waste policy with respect to the present day } \\
\text { situation. The BaU scenario reflects a future in which major socio-economic } \\
\text { drivers follow current trends and assumes that there are no major policy } \\
\text { changes. }\end{array}$ \\
\hline Supportive legislation & $\begin{array}{l}\text { This scenario assumes that further policies will be implemented to support food } \\
\text { donation/redistribution activities with a strong focus on policies } \\
\text { implementations directed to changes in current legislations hampering } \\
\text { food donation/redistribution. In this case it is assumed that the required } \\
\text { infrastructure to facilitate donation/redistribution (e.g. logistics, capacity, supply } \\
\text { and demand) will be developed by businesses and market forces if they are } \\
\text { obliged to adopt new regulations. }\end{array}$ \\
\hline Supportive infrastructure & $\begin{array}{l}\text { This scenario assumes that further policies will be implemented to support food } \\
\text { donation/redistribution activities with a strong focus on building } \\
\text { infrastructure to facilitate donation/redistribution by means of capacity } \\
\text { building activities and engaging business sector using different market based } \\
\text { instruments/incentives. }\end{array}$ \\
\hline
\end{tabular}

In this setting the Business as Usual scenario might be seen clearly as a worst case. The current situation might be characterized by limited food waste reduction possibilities related to (i) ongoing awareness campaigns, (ii) initiatives from social organizations and (iii) national objectives to reduce food waste in certain MSs. Such a scenario would lead to a very fragmented landscape across the EU with only some MSs taking targeted initiatives to address the problem. The direct economic costs for the EC might be relatively limited (close to zero) since no adjustment and/or implementation costs for new legislations would be require. However indirect costs might remain high due to the environmental, social and nutritional impacts of food waste.

The scenarios Supportive legislation and Supportive infrastructure are complementary to each other. Both scenarios offer a significant potential, nevertheless the interviews suggest that the mix of the two might lead to unlock the higher potential in terms of food waste reduction. The major positive change should take place in the scenario "supportive infrastructure" as an evolution of the scenario "supportive legislation". There is ample room for a better integration between infrastructure and legislation to achieve positive outcomes. However a major limitation might be represented by the substantial investments required to develop and maintain these infrastructures. A comprehensive assessment of the environmental and social costs related to food waste and poverty could provide important evidences to justify and motivate these investments.

\section{Setting: A Multi-target approach towards reducing food waste}

Within the setting Multi-target approach towards reducing food waste identified drivers include:

1. (lack of) food waste quantification across the food supply chain;

2. (confusion related to) date marking and food labelling;

3. (lack of guidance on) food waste valorisation solutions.

On the basis of these drivers three scenarios were identified and developed (see Table ES2). 
Table ES2. Scenarios for Multi-target approach towards reducing food waste

\begin{tabular}{|l|l|}
\hline Business as usual & $\begin{array}{l}\text { Summary of hypotheses - Multi-target approach towards reducing food } \\
\text { waste }\end{array}$ \\
\hline & $\begin{array}{l}\text { No significant changes in the food waste policy with respect to the present day } \\
\text { situation. The BaU scenario reflects a future in which major socio-economic } \\
\text { drivers follow current trends and assumes that there are no major policy } \\
\text { changes. }\end{array}$ \\
\hline $\begin{array}{l}\text { Increased food waste } \\
\text { quantification in EU-28 }\end{array}$ & $\begin{array}{l}\text { Member States and actors across the food chain increase their efforts in } \\
\text { quantifying food waste at the most optimized level. }\end{array}$ \\
\hline $\begin{array}{l}\text { Clarification and } \\
\text { simplification of "date } \\
\text { marking" }\end{array}$ & $\begin{array}{l}\text { A better understanding of date marking on the consumer level would be } \\
\text { enhanced by joint efforts from relevant actors, including food producers, and } \\
\text { national regulatory authorities. }\end{array}$ \\
\hline $\begin{array}{l}\text { Guidance on valorisation } \\
\text { solutions }\end{array}$ & $\begin{array}{l}\text { More science-based research will support food chain actors to recover food waste } \\
\text { at the highest possible level. }\end{array}$ \\
\hline
\end{tabular}

In this setting the Business as Usual scenario will have a negative impact on food waste reduction, although awareness raising has increased during the previous years thanks to different food waste related projects and initiatives. However, in the long run, without additional support from governments to implement targeted policy interventions food waste might tend to increase. The economic, social and environmental impacts are assessed as limited.

The scenario Increased food waste quantification in EU-28 assumes moderate food waste reduction across the entire supply chain with the highest impact expected at retail level and the lowest at the primary production. The economic impact in terms of costs will also vary across the entire supply chain, with the manufacturing sector expected to face the higher initial costs due to the application of the FUSIONS quantification manual methodologies and the retail sector presenting slightly lower costs , although data need to be gathered and analyzed in most of the cases are already available. The social impact of this scenario is expected to be positive due to increased employment opportunities for consultancies and research organisations. Environmental impact is expected to range between moderate to largely positive thanks to the optimised quantification practices related to the application of harmonised quantification methodologies.

The scenario Clarification and simplification of date marking is characterized by significant positive change in food waste reduction, with the highest impact expected at wholesale and retail level. The impact on the household level is also expected to be relatively high but only in case of the implementation of consumer focused trainings on date labels. The potential costs for the EU and for MSs are relatively high as a result of a wide consultation across all MSs competent authorities, food businesses and trade bodies regarding the enforcement of the new legislation. Social impact is expected to range between slightly negative (e.g. compromising food safety) and slightly positive for the potential creation of employment opportunities for consultancies, research organisations, and social entrepreneurs that could be asked to provide additional solutions to complement and reinforce existent actions. The environmental impact is expected to range between moderate to large due to optimised date marking practices with the application of the improved guidance.

The scenario Guidance on valorisation solutions is characterized by a positive impact on food waste reduction across the entire supply chain. The primary production sector will highly benefit from new valorisation solutions and alternative markets for unsaleable products will have a positive influence on food waste reduction (e.g. in the meat and fresh fruit \& vegetables sectors). Similar expectations are foreseen for the processing sector as more food surplus is produced at this level. The overall cost for the EC is expected to be relatively high in particular for certain valorization streams as those based on animal by-products. Social impact will be relatively positive especially due to the creation of new employment opportunities. A large positive change is expected in terms of environmental impact for instance due to the generation of energy via anaerobic digestion and other innovative forms of valorization that may reduce the amount of natural resources currently used. 
The scenario analysis lead to the identification of a set of emerging issues to be considered for the development of potential recommendations:

- Very strong incentives for donation may cause actors to decrease other food waste prevention efforts (efforts to decrease food waste generation in the first place). Besides, strong regulations to decrease food waste in the chain via regulations, may rise other problems such as that edible food may be used not for donation purposes, but for feed or composting. Hereby it is important to ensure that policy interventions consider the food hierarchy.

- The revision of policy and legislations supporting food donation and redistribution activities should be based on an extended dialogue among different policy domains: environment, economy, poverty, health etc. A better coordination would reduce the risk of irreversible effects and perverse subsidies. Moreover revised legislations should not favour one stakeholder specifically and should define fair rules for all organizations engaged with food donation and redistribution.

- A mix of "supportive legislation" and "supportive infrastructure" offers high potential for food waste reduction via food donation and redistribution, where the major positive change should take place in "supportive infrastructure" as an evolution of the scenario "supportive legislation". This may require substantial costs and incentives from government. There is ample room for a better integration between infrastructure and legislation to achieve positive outcomes. However a major limitation might be represented by the substantial investments required to develop and maintain these infrastructures. A comprehensive assessment of the environmental and social costs related to food waste and poverty could provide important evidences to justify and motivate these investments.

- Suasive measures matters. A relevant role in food waste reduction can be played by the stimulation of dialogue around food donation and redistribution by creating guidelines for donation, supporting online platforms, open dialogue on the EU level concerning lessons learned along with potential areas of development.

- The introduction of voluntary agreements between manufactures and food banks can provide good potential to increase the effectiveness of food donation and redistribution activities.

- The introduction of a harmonized methodology for the quantification of food waste represent a crucial step to improve the position of food waste in the agenda of policy makers and therefore to stimulate food waste reduction through the initiatives undertaken by food donation and redistribution activities.

- Date marking has less to do with 'use by' versus 'best before' confusion and more to do with product like extension and the operation of 'minimum life on receipt criteria' imposed by retailers on their suppliers, the 'buffer' time that is assumed between total product life and the date life used on the product. For many products this buffer exceeds food safety requirements by a significant margin and could be safely reduced on some product types. This argument is part of the 'clarification' issue on date markings and has significant implications on supply chain food waste and consumer food waste for more perishable products.

- Life cycle cost analysis might shed light on which valorisation solutions are more profitable and for which sector of the food supply chain.

- Experts suggest that general economic and environmental advantages from recycling catering and household food waste into animal feed, would only be possible if the EU Regulations on ABPs were to be revised (Reg. 1069/2009 and implementing Reg 142/2011). 


\section{Introduction and scope}

Food waste is gathering increasing global interest and is engaging governments, research institutions, producers, distributors, retailers and consumers in its definition and in the identification of appropriate policy interventions for its prevention and reduction.

FUSIONS (Food Use for Social Innovation by Optimising Waste Prevention Strategies) project aims at contributing to a more resource efficient Europe by significantly reducing food waste through a range of activities, including the harmonisation of food waste monitoring, the understanding of the extent to which social innovation can reduce food waste, and the development of a set of guidelines for a Common Food Waste policy for EU-28. Within this framework the project is specifically looking at social innovation and at policies stimulating social innovation initiatives addressing food waste.

This report presents a scenario analysis carried out in the framework of FUSIONS Work Package (WP) 3, Task 3.1.2 "Scenario analysis on current trends of food waste generation".

According to the Document of Work, scenarios are based on the T3.1 country surveys, the context and impact information derived from T1.2, T1.3, T1.4, and on appropriate policy and socio-economic drivers as described in T1.5. The scenario analysis represents an attempt to identify the most promising policy interventions to address the most relevant food waste drivers and thus to contribute to the reduction of food waste.

What is the objective of the scenario analysis?

FUSIONS "Scenario analysis on current trends of food waste generation" aims at identifying and analysing targeted policy interventions addressing the most relevant food waste drivers by developing a narrative focusing on two selected settings: food donations in a context of social innovation and multi-target approach towards reducing food waste.

The analysis is based on a qualitative comparative method which assesses a number of alternative scenarios focusing on selected policy interventions in order to evaluate food waste reduction possibilities in Europe in light of the $50 \%$ food waste reduction by 2030 at retail and consumer level as foreseen by the SDG goals.

This activity was originally planned to be developed in the first part of the project with a delivery date set for month 24 (July 2014).

Why was the activity postponed at the end of the project?

Early during the project implementation it became clear that a postponement of the scenario work at the end of the project would have ensured enormous benefits since it would have had the opportunity to receive inputs and information from most of the activities carried out within FUSIONS in terms of food waste definition, quantification and monitoring (FUSIONS WP1), contribution of social innovation to food waste reduction and prevention (FUSIONS WP4), policy approaches (FUSIONS WP3) and consultation with a variety of stakeholders participating to the different consultations held at the different regional and European platforms (FUSIONS WP2).

Why the choice of a qualitative approach?

A qualitative approach was considered the most appropriate solution considering data quality and availability two years after the beginning of the project. Food waste estimates at that time (20142015) were available only for few EU Member States and were generally relying on different methodologies, thus not allowing data comparability. Within the FUSIONS project the activity related to the estimation of EU data on food waste was completed in March 2015. FUSIONS report "Estimates of European food waste levels" provides a relatively consistent approximation of the level of food waste in the EU-28 (there is moderately high uncertainty around estimates of food waste amounts; the approximate $95 \%$ confidence interval is \pm 14 million tonnes (or $\pm 16 \%$ ). Therefore, the range of results within this confidence interval is from 74 million tonnes to 101 million tonnes). However a relatively high level of uncertainty is related to the small number of recent studies of sufficiently high quality being identified, on the relatively limited number of MS providing quality data (about one quarter) and on the process of scaling up the information from these MS to the whole EU-28 (Åsa Stenmarck et al, 2016).

FUSIONS - Scenario analysis on current trends of food waste generation | 10 
Why the identification of specific settings?

Literature (Ian Miles et al., 2003) suggests to maintain a narrow focus when building scenarios so to prevent broader generalizations. In the identification of the setting it is important to determine the time horizon for the scenarios and the boundaries of the object of analysis identifying and understanding those uncertainties that might characterize the mid-long-term future. It is therefore important to identify and discuss the drivers/factors that: a) are currently leading to a situation/problem; b) should be changed to improve the current situation.

In the case of food waste the need for the identification of specific "settings" (1. Food donation/redistribution in a context of social innovation and 2. Multi-target approach towards reducing food waste) to narrow down the object of analysis of the scenario work is suggested by the lack of reliable data, but also by the complexity of the food (waste) sector. Drivers are many and different in the each food supply chain segments and legislation and policies addressing food waste are multilevel and multi-sectoral. Therefore, there are multiple - and not always explicit - policy effects to be considered.

FUSIONS "Drivers of current food waste generation, threats of future increase and opportunities for reduction" identifies "271 food waste drivers, which witness a wide, multifaceted problem, interconnected with all stages of the food supply chain, from primary production in farms, up to final consumption in food services and households" (Canali et al., 2014). FUSIONS "Review of EU legislation and policies" detects "52 legislative acts with implications for food waste that have been issued and applied within seven of the twenty areas (Chapters) covered by EU legislation and policies" (Vittuari et al, 2015).

In which context was the approach to the scenario analysis discussed?

The planning phase of the scenario work was characterized by extensive discussions based on the identification of the approach (quantitative vs. qualitative methodologies), of specific "settings" and "key questions".

Inputs came from:

- FUSIONS WP3 Core Partners meetings;

- FUSIONS Executive Board meetings;

- FUSIONS External Experts Advisory Board meetings;

- FUSIONS Regional and European Platform meetings.

Based on the inputs above the following two settings were identified:

1. Food donation/redistribution in a context of social innovation;

2. Multi-target approach towards reducing food waste.

These two settings are described in detail in Section 3.

Which information sources were used to identify the settings?

Scenario setting identification was based on several information sources including:

- Experts' opinions from FUSIONS partners, FUSIONS Executive Board and External Advisory Board members, food chain stakeholders participating to the different FUSIONS Regional and European Platform meetings;

- FUSIONS deliverables:

a. The definition of food waste developed within FUSIONS 1.1;

b. The drivers identified in FUSIONS D1.5;

c. The review of legislation and policies addressing food waste conducted in FUSIONS D3.1 Review of EU legislation and policies addressing food waste;

d. the outcomes of the Social Innovation Camp as emphasized in FUSIONS D3.2 (D3.2 Social Innovation Camp and comprehensive set of measures on which to build policy strategies);

e. FUSIONS D3.3: Review of policy approaches to address food waste prevention and reduction: market based instruments and options to stimulate social innovation initiatives;

f. FUSIONS D4.1 Report on categorized and catalogued examples of social innovation;

g. Preliminary inputs from D4.3 Evaluation report detailing the results and impacts of the implemented feasibility studies.

- Literature on food waste. 


\section{Methodology}

This section describes the core of the scenario analysis and the steps undertaken to carry out the analysis.

What is a scenario analysis

Scenario analysis is a strategic management tool that organizations can use to create a better understanding of potential 'futures'. This method does not predict the future, but it can help managers and decision makers to explore a range of plausible futures in the context they analyse. Thus a scenario is a description of a future situation and the course of events which allows one to move forward from the original situation to the future situation (Godet et al., 1996; Mietzner and Reger, 2005; Meyer, 2007). In 1993 Shoemaker has described scenarios as "focused descriptions of fundamentally different futures presented in coherent script-like or narrative fashion" (Shoemaker 1993, p. 195). In general, the method helps to formulate hypothesis on how the future 'could be', given all its uncertainties and complexities. It helps to identify issues that need attention in strategy or policy development, in this case regarding the policy measures to reduce food waste.

The development of scenario analysis starts with the following steps (Mietzner and Reger, 2005):

1. clarification of the purpose;

2. decision of the time horizon;

3. description of the trends;

4. definition of the current situation (baseline scenario);

5. identification of the forces driving the sector;

6. identification of the uncertainties (i.e. less predictable variables that may have an influence);

7. definition of the links between driving forces;

8. identification and description of the coherent scenarios and choose strategic actions.

First, the purpose of the study and the time horizon have to be defined. It's also important, in the early stages, to have a clear picture of the past and present trends of the sector; this will provide information for future analysis helping to build the baseline scenario. The identification of the driving forces, defined as "key internal forces" (such as knowledge and competence of management and workforce) and external forces (such as economy, competitors, technology) that shape the future of an organization", is usually done with experts' consultation. Experts can be consulted by means of questionnaires, personal interviews, web panels and polls, focus groups or Delphi interviews. In addition, a literature review may provide information on the main variables.

\section{Methodological steps}

The study has been carried out using the following methodological steps (see Table 2.1):

1. food waste drivers selection and setting's boundaries identification;

2. system map development;

3. baseline development;

4. scenario building (narrative);

5. analysis of scenarios. 
Table 2.1 Methodological steps and main sources of evidence

\begin{tabular}{|c|c|c|}
\hline Step & Main source & Note \\
\hline $\begin{array}{l}\text { 1. Food waste drivers selection and } \\
\text { setting's boundaries identification }\end{array}$ & FUSIONS D1.5 and other literature & $\begin{array}{l}\text { The same methodology was applied } \\
\text { for the two settings }\end{array}$ \\
\hline $\begin{array}{l}\text { 2. System map development } \\
\text { (specific for each setting) }\end{array}$ & Author elaboration based on step 1 & $\begin{array}{l}\text { The same methodology was applied } \\
\text { for the two settings }\end{array}$ \\
\hline 3. Baseline development & $\begin{array}{l}\text { Author elaboration based on step } 1 \\
\text { and } 2\end{array}$ & $\begin{array}{l}\text { The same methodology was applied } \\
\text { for the two settings }\end{array}$ \\
\hline \multirow[t]{2}{*}{ 4. Scenario building (narrative) } & $\begin{array}{l}\text { FUSIONS for the narrative of the } \\
\text { scenarios of setting A (Food } \\
\text { donation/redistribution in a context } \\
\text { of social innovation) }\end{array}$ & \multirow[t]{2}{*}{ Please see Step 5} \\
\hline & $\begin{array}{l}\text { FUSIONS } \text { (for the } \mathrm{BaU} \text { ) and } \\
\text { REFRESH DoA Part B (Multi-target } \\
\text { approach towards reducing food } \\
\text { waste) }\end{array}$ & \\
\hline \multicolumn{3}{|l|}{ 5. Analysis of scenarios } \\
\hline $\begin{array}{l}\text { Setting A "Food donation and } \\
\text { redistribution in a context of social } \\
\text { innovation" }\end{array}$ & $\begin{array}{l}\text { Impact assessment matrix based on } \\
\text { interviews to individual experts / } \\
\text { focus group (including a } \\
\text { consultation session at the } \\
\text { FUSIONS EPM 2016) }\end{array}$ & \\
\hline $\begin{array}{l}\text { Setting B "Multi-target approach } \\
\text { towards reducing food waste" }\end{array}$ & $\begin{array}{l}\text { Impact assessment matrix based on } \\
\text { interviews to individual experts }\end{array}$ & \\
\hline
\end{tabular}

Step 1. 1. Food waste drivers selection and setting's boundaries identification

Step 1 includes the selection of the major food waste drivers and the identification of the specific settings.

In order to be able to provide the current trends of food waste and to develop a baseline situation for the scenarios, the study built on the inventory and selection of: food waste drivers developed in D1.5 (Canali et al., 2014, "Drivers of current food waste generation, threats of future increase and opportunities for reduction") and policies addressing these drivers (inputs from D3.1; D3.2, D3.3 of FUSIONS projects-see http://www.eu-fusions.org/index.php/publications).

Specific settings were identified due to the complexity of the food sector, and food waste in particular, and to prevent broader generalizations in building scenarios.

Table 2.2 Food waste drivers and related policy measures

\begin{tabular}{|c|c|c|c|c|}
\hline $\begin{array}{l}\text { Most } \\
\text { relevant } \\
\text { FW } \\
\text { drivers }\end{array}$ & $\begin{array}{l}\text { Why is it relevant? How } \\
\text { does it cause food } \\
\text { waste? }\end{array}$ & $\begin{array}{l}\text { Can this driver } \\
\text { be addressed } \\
\text { by a policy } \\
\text { measure? }\end{array}$ & $\begin{array}{l}\text { What policy } \\
\text { measures? }\end{array}$ & $\begin{array}{l}\text { Please, provide a explanation } \\
\text { of how policy measure can } \\
\text { address this food waste driver }\end{array}$ \\
\hline $\begin{array}{l}\text { Lack of tax } \\
\text { breaks }\end{array}$ & $\begin{array}{l}\text { Lack of tax breaks on } \\
\text { donations makes transfer } \\
\text { of food waste from farms } \\
\text { to charities not } \\
\text { economically attractive }\end{array}$ & Yes & $\begin{array}{l}\text { Tax Breaks } \\
\text { for donations }\end{array}$ & $\begin{array}{l}\text { Businesses claim that it costs } \\
\text { them to redistribute. If tax breaks } \\
\text { exist then this provides an } \\
\text { incentive or at least offsets costs, } \\
\text { perceived or actual, of } \\
\text { redistributing. }\end{array}$ \\
\hline$\ldots$ & $\ldots$ & $\ldots$ & $\ldots$ & $\ldots$ \\
\hline
\end{tabular}

Step 2. System Map Development

A system map is a visual description of a system that provides a graphical representation of the correlations among the main drivers and other key elements. It can contain different actors involved, their mutual links and the flows of materials, energy, information and money through the system (Morris and Martin, 2009).

Based on the information on food waste drivers and policies, system maps were developed for each setting of food waste in order to provide a visual representation of the causal linkages among the different drivers and policies characterizing food waste prevention and reduction. 
Step 3. Baseline development

Based on the collected information a baseline situation reflecting current trends of the food waste generation has been sketched. This process is visually illustrated in Figure 2.1.

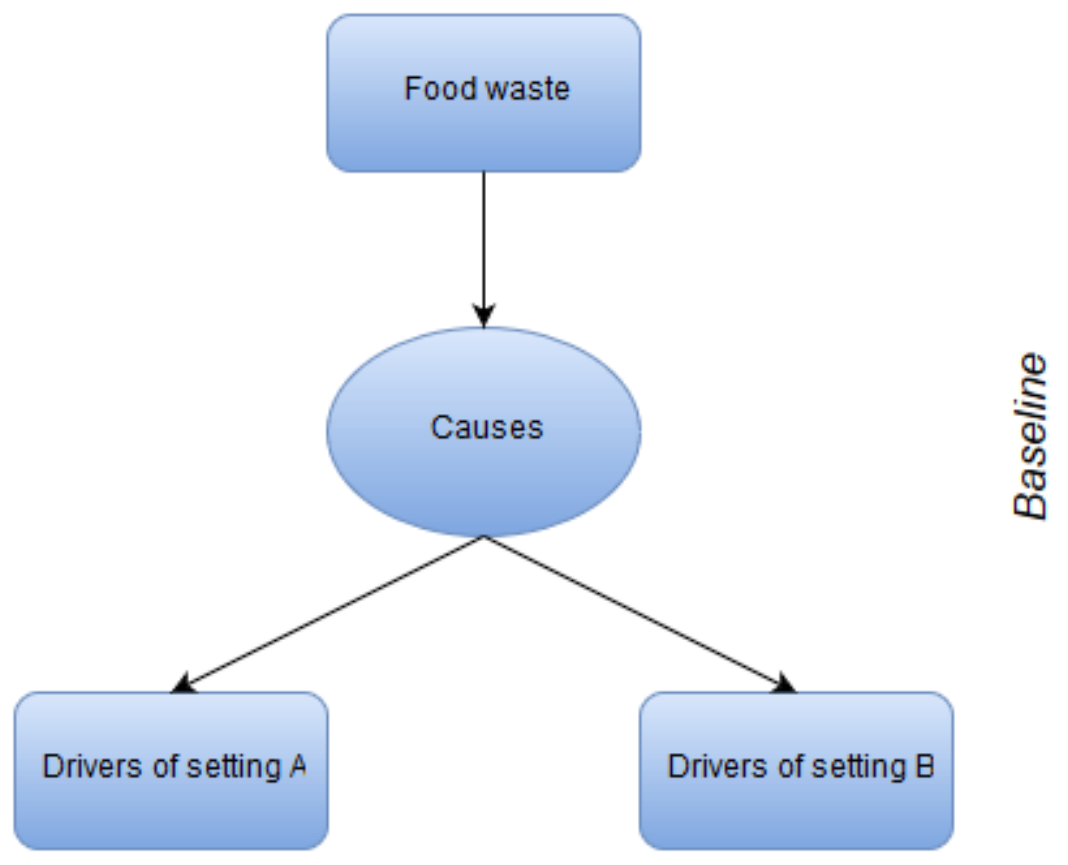

Figure 2.1 Baseline development

Step 4. Scenario building (narrative)

The baseline information has been used to construct the narratives of scenarios. A narrative is a discourse based on a coherent set of assumptions and principles underpinning and communicating a certain worldview (SCAR 2011). Levidow (2008) defines narratives as having three elements:

- descriptive accounts: claims about objective reality as threats, opportunities and imperatives;

- normative accounts: claims about necessary or desirable responses to that objective reality;

- policy instruments for carrying out those responses.

The narrative of each scenario includes the following information:

- a brief introduction (starting from the baseline);

- descriptive accounts of the state of the problem (food waste) and drivers; description and claims about the interactions among drivers and other key factors;

- suggested solutions, e.g. policy instruments referred to assigned setting.

Two settings are characterized by a Business as usual scenario (BaU) and a number of additional scenarios describing different potential futures.

The Business as usual (BaU) scenario is developed for both settings and reflects a future in which major socio-economic drivers follow current trends and assumes that there are no major policy changes. This scenario assumes continued implementation of current policies with implications on food waste.

Beside the BaU, setting A (Food donation and redistribution in a context of social innovation) presents two additional scenarios:

- Supportive legislation: adjustments and or changes will take place in a number of existing policy regulations hampering food waste reduction specific to the setting;

- Supportive infrastructure: no changes will be required in the existing regulations but there will be new supportive legislations developed to support private parties (i.e. supply chain links) to reduce and prevent food waste reduction. 
Setting B (Multi-target approach towards reducing food waste) presents three additional scenarios:

- Increased food waste quantification in EU-28 which assumes that Member states and actors across the food chain increase their efforts in quantifying food waste;

- The Clarification and simplification of date marking scenario, which assumes that there is a better understanding and use of date marking by all relevant actors, including food producers, consumers and national regulatory authorities;

- The Guidance on valorisation solutions scenario, which assumes that more science-based research will support food chain actors to recover food waste at the highest possible value.

Table 2.3 Settings, scenarios and sources of evidence

\begin{tabular}{|c|c|c|}
\hline Setting & Scenario & Source of evidence \\
\hline \multirow{3}{*}{$\begin{array}{l}\text { Food donation/redistribution in a context of } \\
\text { social innovation }\end{array}$} & Business as usual (BaU) & FUSIONS reports and activities \\
\hline & Supportive infrastructure & FUSIONS reports and activities \\
\hline & Supportive legislation & FUSIONS reports and activities \\
\hline \multirow{4}{*}{$\begin{array}{l}\text { Multi-target approach towards reducing } \\
\text { food waste }\end{array}$} & Business as usual (BaU) & FUSIONS reports and activities \\
\hline & $\begin{array}{l}\text { Increased food waste } \\
\text { quantification in EU-28 }\end{array}$ & \multirow{3}{*}{$\begin{array}{l}\text { FUSIONS reports and activities } \\
\text { and REFRESH proposal }\end{array}$} \\
\hline & $\begin{array}{l}\text { Clarification and simplification of } \\
\text { date marking }\end{array}$ & \\
\hline & $\begin{array}{lll}\text { Guidance } & \text { on } & \text { valorisation } \\
\text { solutions } & & \end{array}$ & \\
\hline
\end{tabular}

Step 5. Analysis of scenarios

The scenarios developed in the two settings are analysed through different tools. The comparative assessment is performed within the scenarios of the same setting and not between the different settings.

The scenarios developed in the setting Food donation and redistribution in a context of social innovation are analysed using expert consultation sessions at FUSIONS RPMs and EPM ${ }^{2}$ and individual interviews by means of a Qualitative Impact Assessment Matrix, adapted from BIOIS (2010). The matrix takes into account the perceptions of experts regarding the impact of different scenarios on different aspects and uses a scoring system to evaluate these perceptions.

Also the scenarios developed in the setting Multi-target approach towards reducing food waste are analysed using individual interviews to assess a Qualitative Impact Assessment Matrix

A. Assessment of the scenarios within the setting "Food donation and redistribution in a context of social innovation"

This assessment aimed at evaluating the possible impact from implementation of developed scenarios on food waste prevention and reduction as well as on socio-economics and environment. It is important to note that this assessment has a solely qualitative approach since it is based on experts' perceptions and does not involve any data estimation on actual impacts. The example of the impact assessment matrix and the scoring system for the impact assessment of scenarios are presented in Tables 2.4 and 2.5 respectively.

\footnotetext{
2 RPM (Regional Platform Meetings) in Amsterdam and Vienne (February 11, 2016 and February 25, 2016) and EPM (European Platform meeting) in Brussels, May 20, 2016
} 
Table 2.4 Impact Assessment Matrix Setting A

\begin{tabular}{|c|c|c|c|}
\hline Impacts & $\begin{array}{l}\text { Business } \\
\text { as usual }\end{array}$ & $\begin{array}{c}\text { Supportive } \\
\text { infrastructure }\end{array}$ & $\begin{array}{l}\text { Supportive } \\
\text { legislation }\end{array}$ \\
\hline \multicolumn{4}{|c|}{ Quantitative impact on food waste reduction ( $t$ ) } \\
\hline \multicolumn{4}{|l|}{ Potential food waste reduction } \\
\hline \multicolumn{4}{|l|}{ Economic impact } \\
\hline \multicolumn{4}{|l|}{ Implementation Costs for EU commission } \\
\hline \multicolumn{4}{|l|}{ Implementation Costs for MS } \\
\hline \multicolumn{4}{|c|}{$\begin{array}{l}\text { Implementation Costs for supply chain actors in } \\
\text { MS }\end{array}$} \\
\hline \multicolumn{4}{|l|}{ Impact on household income } \\
\hline \multicolumn{4}{|l|}{ Social impact } \\
\hline \multicolumn{4}{|l|}{ Impact on household behaviour } \\
\hline \multicolumn{4}{|l|}{ Product quality } \\
\hline \multicolumn{4}{|l|}{ Food safety } \\
\hline \multicolumn{4}{|l|}{ Environmental impact } \\
\hline \multicolumn{4}{|l|}{ Efficient natural resource use } \\
\hline \multicolumn{4}{|l|}{ Nutritional impact } \\
\hline \multicolumn{4}{|l|}{ Benefits for needy people } \\
\hline \multicolumn{4}{|l|}{ Other issues } \\
\hline \multicolumn{4}{|l|}{ Feasibility of the scenario } \\
\hline Practicality to implement the scenario & & & \\
\hline
\end{tabular}

Table 2.5 Scoring system for the impact assessment of scenarios for both settings

\begin{tabular}{|l|l|}
\hline+3 & Major positive change \\
\hline+2 & Significant positive change \\
\hline+1 & Positive change \\
\hline 0 & No change \\
\hline-1 & Negative change \\
\hline-2 & Significant negative change \\
\hline NA/NR & Major negative change \\
\hline
\end{tabular}

B. Assessment of scenarios within the setting "Multi-target approach towards reducing food waste"

This assessment aimed at evaluating the possible impact from implementation of a multi-target approach towards reducing food waste as well as on socio-economics and environment. It is important to note that this assessment has a solely qualitative approach since it is based on experts' perceptions and does not involve any data estimation on actual impact. The matrix (Table 2.6) is using the same scoring system as above (Table 2.5)

Table 2.6 Impact Assessment Matrix Setting B

\begin{tabular}{|l|l|l|l|l|}
\hline Impacts & $\begin{array}{c}\text { Business } \\
\text { as Usual }\end{array}$ & $\begin{array}{c}\text { Increased } \\
\text { food waste } \\
\text { quantification } \\
\text { in EU-28 }\end{array}$ & $\begin{array}{c}\text { Clarification } \\
\text { and } \\
\text { simplification } \\
\text { of date } \\
\text { marking }\end{array}$ & $\begin{array}{c}\text { Guidance on } \\
\text { valorisation } \\
\text { solutions }\end{array}$ \\
\hline Quantitative impact on food waste reduction (t) & & & & \\
\hline Primary production & & & & \\
\hline Manufacture/Processing & & & & \\
\hline Retail/wholesale & & & \\
\hline Household & & & \\
\hline
\end{tabular}

FUSIONS - Scenario analysis on current trends of food waste generation | 16 


\begin{tabular}{|c|c|c|c|c|}
\hline Impacts & $\begin{array}{l}\text { Business } \\
\text { as Usual }\end{array}$ & $\begin{array}{c}\text { Increased } \\
\text { food waste } \\
\text { quantification } \\
\text { in EU-28 }\end{array}$ & $\begin{array}{c}\text { Clarification } \\
\text { and } \\
\text { simplification } \\
\text { of date } \\
\text { marking }\end{array}$ & $\begin{array}{c}\text { Guidance on } \\
\text { valorisation } \\
\text { solutions }\end{array}$ \\
\hline \multicolumn{5}{|l|}{ Economic impact } \\
\hline \multicolumn{5}{|c|}{$\begin{array}{l}\text { Implementation costs for food waste reduction } \\
\text { actions at European Commission level }\end{array}$} \\
\hline \multicolumn{5}{|l|}{ Implementation costs for MS } \\
\hline \multicolumn{5}{|l|}{ Costs for food loss in primary production } \\
\hline \multicolumn{5}{|c|}{ Costs for food waste in Manufacture/Processing } \\
\hline \multicolumn{5}{|l|}{ Costs for food waste in Retail/wholesale } \\
\hline \multicolumn{5}{|l|}{ Implementation costs for Household } \\
\hline \multicolumn{5}{|l|}{ Social impact } \\
\hline \multicolumn{5}{|c|}{$\begin{array}{l}\text { Impact on awareness level of food waste/loss } \\
\text { and its consequences amongst consumers }\end{array}$} \\
\hline \multicolumn{5}{|l|}{ Impact on product quality and food safety } \\
\hline \multicolumn{5}{|l|}{ Impact on employment } \\
\hline \multicolumn{5}{|l|}{ Environmental impact } \\
\hline \multicolumn{5}{|l|}{ Impact on efficient natural resource use } \\
\hline \multicolumn{5}{|l|}{ Impact on GHG emission } \\
\hline \multicolumn{5}{|l|}{ Other issues } \\
\hline \multicolumn{5}{|l|}{ Feasibility of the scenario } \\
\hline Practicality to implement the scenario & & & & \\
\hline
\end{tabular}




\section{Food waste drivers selection and setting identification}

Food waste is an issue of importance to global food security and good environmental governance, directly linked with environmental issues (e.g. energy, climate change, water, availability of resources), economic aspects (e.g. resource efficiency, price volatility, increasing costs, consumption, waste management, commodity markets) and social impacts (e.g. health, equality) (Stenmarck, et al., 2016).

Different studies have shown that approximately one third of the world food production is not consumed (Gustavsson et al, 2011; Bio Intelligence study, 2010). This leads to negative impacts on environment, inefficient uses of resources and negative costs throughout the food supply chain including households. There is a pressing need to prevent and reduce food waste to make the transition to a resource efficient Europe. FUSIONS studies reviled that a very important role in preventing and reducing food waste is played by governments and governmental policies (FUSIONS D3.1, D3.3).

\section{Which suggestions from food waste drivers?}

In order to analyse the food waste problem and to find solutions to reduce and prevent food waste there is a need to identify the most important triggers of food waste generation, then to explore how these triggers can be addressed. In relation to this, it can be affirmed that:

- The generation of food waste depends on one hand on socio economic trends such as population and economic growth, increasing global sourcing, consumption per capita, the evolution of technologies (influencing food production/supply), the evolution of food production/supply and on the other hand it depends on multiple drivers that can be categorised in 4 main groups (FUSIONS D1.5): 1) Technological 2) Institutional (business and management) 3) Institutional (legislation and policy) 4) Social (consumers' behaviours and lifestyles)

- The prevention and reduction of food waste depend on how the above mentioned drivers can be addressed. Since the focus of our study is on food prevention and reduction by means of policies, only the policy measures addressing food waste prevention and reduction are taken into account.

Food waste drivers affecting food waste generation can be divided between those having a direct influence on a specific issue (micro-environmental key forces) and those related to global trends (macro-environmental key forces) (Canali et al., 2014). Micro-environmental key forces may include inefficiencies and surplus in food supply chains, households and consumers behaviour, institutional and policy factors. Macro-environmental key forces can be related to social, political, economic and environmental trends.

Although these factors are deeply interconnected and can influence each other - for instance inefficiencies and surplus can represent the result of socio-economic trends, policy factors or consumer behaviour - such a classification can provide inputs to identify the boundaries of specific settings to maintain a narrow focus simplifying the object under analysis and avoiding the risk of getting lost in broader generalizations.

How is "policy" defined within FUSIONS?

FUSIONS adopted a working definition of policy identifying policy as "actions undertaken by governments and public authorities and organisations such as regulations/legislations, governmental subsidies and support actions, private initiatives".

Policy instruments were characterized according their approaches (Gupta, et al., 2013), as summarized in Figure 3.1. 


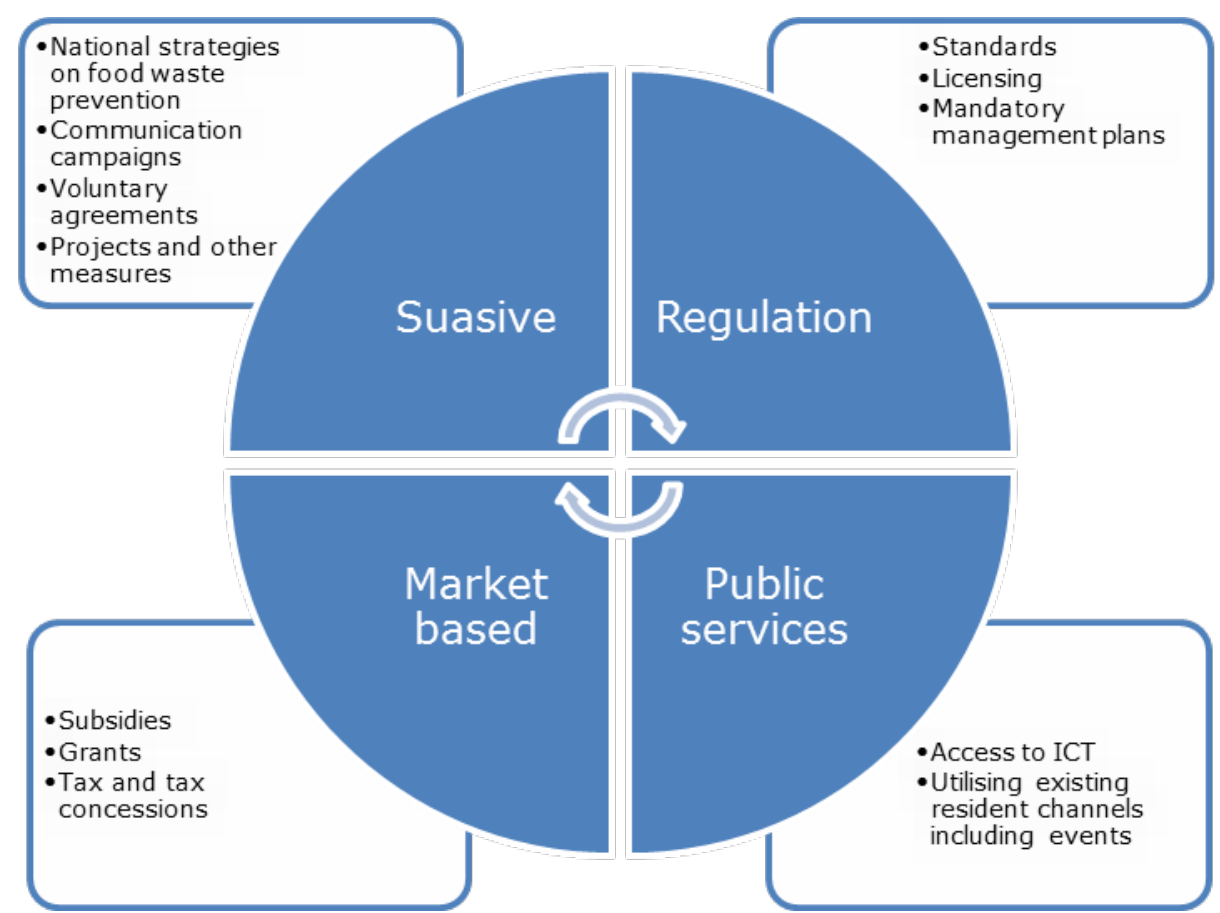

Figure 3.1 Policy instruments according to different approaches

- Suasive approaches: policy tools that encourage changes in behaviour through the provision of information, such as via general education programs, guidelines and codes of practice, training programs, extension services and research and development. The suasive policy measures include:

- National strategies on food waste prevention: methods, strategies or plans specifically addressing food waste prevention. Key sectors addressed in the plan should include local authorities, households, the hospitality industry, the retail supply chain, businesses and institutions (such as schools and hospitals).

- Communication and campaigns: national "umbrella" campaigns; local campaigns; short campaigns and festivals; education and training activities; contests and competitions; exhibitions, whose aim is to raise awareness on food waste.

- Voluntary agreements: alternative courses of actions such as self-regulations developed by the industry generally aimed to deliver the policy objectives faster and/or in a more costeffective manner compared to mandatory requirements.

- Projects and other measures: initiatives like neighbourhood projects, food sharing platforms, platform/networks, labelling, applications, etc. that contribute and/or are connected to food waste reduction.

- Regulatory approaches: require changes in behaviour by introducing penalties for parties who do not comply with regulatory provisions. Regulations and regulatory instruments are governmental or ministerial orders backed by the force of law. Regulatory instruments are sometimes called "command-and-control"; public authorities mandate the performance to be achieved or the technologies to be used. Types of regulatory instruments include standards (including planning instruments), licensing, mandatory management plans and covenants.

- Market-based instruments: policy tools that encourage behavioural change through market signals rather than through explicit directives. There are a range of types of market-based instruments including trading schemes, offset schemes, subsidies and grants, accreditation systems, stewardship payments, taxes and tax concessions.

- Public provision of services: often used when the management solution has the characteristics of a 'public good' which makes it difficult for the private sector to provide the service, e.g. national parks. 


\subsection{Drivers of food waste generation}

FUSIONS D1.5 (Canali et al., 2014) identified a total 105 drivers for the current causes of food waste generation suggesting a classification in three groups: technological drivers, institutional drivers (business management as well as policy and legislation) and social drivers.

There is of course an interrelation of the three classes due to the complexity of the worldwide food supply chain. For example, technological drivers include "drivers of food waste which are inherent to the process design and a consequence of technologies utilised. In this case, food waste can be considered a technological collateral effect of modern production practices, which is accepted by enterprises and consumers according to a cost/benefit ratio." (Canali et al., 2014). There is a close relationship with institutional drivers which contain "drivers of food waste which can be addressed at the macro level (e.g. by policy measures, inter-professional agreements, social campaigns) and not at the level of the single business unit. Examples are the drivers originated by different government policies (agriculture, waste, taxation), market conditions, and unequal bargaining power of food supply chain operators." (Canali et al., 2014). So it can be concluded that the existing food supply system in general influences the generation of food waste.

Technological drivers and drivers in a business context can be grouped into drivers which lead to food waste because food is no longer suitable for human consumption (e.g. inefficient cleaning of equipment which leads to product contamination) and drivers which lead to unsold food without affecting the food safety, taste or nutritional value of the food. Inefficient forecast of demand and therefore surplus in production/stocking amounts along with restricted expiration date lead to relevant amounts of food waste. This topic also includes the tricky prediction of the demand of promotions or seasonal products. If the assumption is wrong, large amounts of products will be overproduced/overstocked. As the suitability for human consumption is not affected, business policy related to food waste prevention could include good cooperation with the provider/client in order to minimise overproduction/stocking as well as timely donation and redistribution of the products.

Institutional drivers as mentioned above relate largely to governmental policies that contribute to food waste generation. Below some examples of such drivers are presented.

Due to increasing protests related to food waste generation, the European Union cancelled certain marketing standards for 26 fruits and vegetables which regulated a very detailed classification and labelling of the products on July 1st 2009 (BMLFUW, 2008). As only high class products could be marketed with profit, products which did not fit into the highest classes often were sorted out already in the stage of primary production and directed to processing, animal feed or disposal. The certain marketing standards were replaced by general marketing standards which only regulate the sound condition for consumption of the product (in practice, most European retailers stick to the old behaviour and still use strict marketing in order to avoid any change in well-established practises). Nevertheless, the topic provides large potential for alternative marketing for wonky products which include gleaning and/or processing of food into meals, juices, jams etc. Some retailers started trials to market wonky products as own trade mark such as REWE in Austria which sells wonky carrots, potatoes, onions, apples and others according to seasonal availability (Matousek, 2014). This means that remaining amounts of wonky products could be available for redistribution purposes.

The topic also includes waste bread from retailers or bakeries. In this case it has to be considered that only products which were not exposed to end consumers are allowed to be redistributed (Scherhaufer and Schneider, 2011).

The re-launch of packaging design should lead to new-fashioned style of common products and increasing purchases. But it also initiates that products in the former packaging become "oldfashioned" in direct relation. As the suitability for human consumption of the former styled products is not affected at all, business policy related to food waste prevention should include good cooperation with the provider/client in order to minimise remaining stocks as well as timely donation and redistribution of the products.

Social drivers are mostly linked to consumer preferences and behaviour. It is always controversial to understand if consumer preferences related to absolutely perfect products were initiated first by business strategies or vice versa.

Along with the preference for ideal shaped products the consumer is used to choose from a large variety of very fresh products 24 hours a day and seven days a week. This habit was supported by the retail development over the last decades and leads to surplus amounts in the shelves related to low

FUSIONS - Scenario analysis on current trends of food waste generation | 20 
sales quantity and short expiration dates (cf. Scherhaufer and Schneider, 2011). A similar phenomenon can be recognised in the hospitality sector where clients' expectations related to perpetual availability of a broad variety of food on the menu as well as large portion sizes and insecure demand forecast options contribute indirectly to food waste generation (cf. Kranert et al., 2012).

Although total waste amounts have to be reported by industry and businesses to environmental authority, the records don't allow to distinguish between suitable or unsuitable food for redistribution so far. As the general public considers food wastage a serious ethical problem, mandatory reporting and publishing induce a potential image problem for companies that are wasting a lot and/or do not donate for redistribution.

\subsection{Socio-economic trends}

Socio-economic trends that may affect food consumption and therefore food waste in the EU and beyond are listed as follows:

Population and economic growth

The issue of population-development interactions assumes particular importance if one wishes to explore scenarios of food and agriculture futures under alternative population projections. Growth calculation models by the Population Division of the United Nations show a world population prognosis peaking at 9,3 billion people by the year 2050 (medium growth scenario). There are also High and Low Variants of future population. They suggest that the world population could be in the range of 7.07.4 billion by 2015 and by 2030 in the range of 7.7-8.9 billion (Van Gogh et al, 2013). The population in EU will decrease slightly (according to Word Bank projection it will be 502,9 mln compared to current $509 \mathrm{mln}$ ).

In terms of economic growth, according to some projections to 2050 , the world would be immensely richer and characterized by less pronounced relative income gaps between developed and countries currently classified as "developing", many of which will no longer belong to this group in the future. GDP in 2050 is projected to be a multiple of the current levels, and developing countries are expected to grow faster than developed ones. While in relative terms there will be convergence in per capita incomes, absolute gaps will continue increasing (FAO, 2012).

Food consumption, changing consumer preferences and dietary patterns

Food consumption expressed in kilocalories (kcal) per capita per day is a key variable used for measuring and evaluating the evolution of the global and regional food situation. Analysis of FAOSTAT data shows that dietary energy measured in kcals per capita per day has been steadily increasing on a worldwide basis; availability of calories per capita from the mid-1960s to the late 1990s increased globally by approximately $450 \mathrm{kcal}$ per capita per day and it has increased by over 600 extra kcal per capita per day in developing countries (FAO, 20033). Currently world consumption growth outpaces population growth for the major commodity groups, with vegetable oils being the most extreme case (EU Agricultural Markets Briefs, $2015^{4}$ ). Dairy and meat products show opposite trends, with consumption growth of dairy increasing over the different periods and that of meat decreasing.

World meat consumption growth continues to decline to nearly reach the pace of population growth in the current period. Consumption dynamics differ considerably between developed and developing countries (EU Agricultural Markets Briefs, 2015). The split confirms the reduction in meat consumption growth to a level slightly above population growth, both in developed and developing countries. The decrease in developing countries is however more significant, and mainly attributed to beef and poultry.

For dairy products the most popular processed dairy product is cheese; consumption of cheese, a high value added product, is growing faster in the developing countries, but consumption is still marginal compared to developed countries (EU Agricultural Markets Briefs, 2015).

\footnotetext{
3 ftp://ftp.fao.org/docrep/fao/005/ac911e/ac911e00.pdf

${ }^{4}$ http://ec.europa.eu/agriculture/markets-and-prices/market-briefs/pdf/06_en.pdf
} 
Summarising the consumption patterns it can be concluded that the market demand for food will continue to grow. To this trend it also contributes a shift of lifestyles and diet patterns of the rising middle class in emerging economies, which will give rise to the shift into higher protein products.

\section{Increased volatility of food prices}

Projections by the World Bank indicate that food prices may rise from $30 \%$ to $50 \%$ in the decades to come. This rise is characterised by high levels of nominal and real (deflated) prices and unprecedented volatility in price movements (van Gogh et al, 2013). This suggests that stability in food prices will no longer prevail. Higher prices and increased volatility will be due to economic growth, shifting of dietary patterns in developing countries, and changing biofuel policies throughout the world. A strong supply response is not expected soon. This will bring about a shift in the global food system, inducing an intensified battle for agri-commodities (van Gogh et al, 2013)

\section{Increasing global sourcing of fresh fruit and vegetables}

The internationalisation of trade has substantially affected the complexity of (food) supply chains. Where supply chains in Western countries are shifting more and more away from local suppliers to the global arena, trade companies increasingly invest in supply chains abroad and in securing a steady supply of good quality product. Driven by consumers and retailers to provide a year-round good quality range of products, trade companies invest in steady supplier relationships. Even where farmers remain linked only to domestic markets, those markets are likely to change, partly in response to changes in demand (reflecting income growth and urbanisation) and supply (competition from global markets absorbing more domestic production) (van Gogh et al, 2013).

\section{Concentration in the global supply chain}

Highly concentrated agro-industrial firms and retailers are having an increasingly dominant role in food systems. Increasing retail power is not confined to developed countries. Retailing is not the only part of agribusiness showing increasing concentration. Upstream parts of the value chain, such as seed supply, show similar trends, as well as downstream at the opposite end of the value chains. Here the growth of large chains in the fast-food sector and their sourcing policies have their impact on how local agricultural production is driven towards larger production units (van Gogh et al, 2013).

\subsection{Settings identification}

Which scenario settings?

Expert opinions, consultations and literature review suggested the identification of two settings with different characteristics:

- Social innovation and food redistribution activities in a context of Social Innovation.

- Multi-target approach towards reducing food waste

Why a focus on the social innovation and food redistribution?

The focus of the FUSIONS project is on "Food Use for Social Innovation by Optimising Waste Prevention Strategies" therefore one setting had to be based on social innovation in connection with food redistribution activities. The decision to link social innovation and food redistribution initiatives is largely based on the nature and results of the social innovation feasibility studies that have been carried out within FUSIONS.

Most of the feasibility studies are connected with food redistribution and suggest that inefficiencies and surplus in food supply chains can be addressed by diffusion of Social Innovation (SI) and related stimulation of donation and redistribution activities.

Why a Multi-target approach towards reducing food waste?

Since food waste drivers are related both to micro and macro-environmental key forces, approaches based on a holistic view of the food chain should be taken into consideration. To some extent a setting inspired by the introduction of the Circular Economy Package (CEP) by European Commission is deemed to provide relevant inputs.

The Circular Economy Package was adopted on the $2^{\text {nd }}$ of December 2015 by the European Commission and represents a milestone in the European economic and political framework.

The Circular Economy Package includes revised legislative proposals on waste, as well as a comprehensive Action Plan setting out a concrete mandate for this Commission's term of office. The 
Commission will develop a common EU methodology to measure food waste and define relevant indicators, will create a platform bringing together Member States and all actors of the food chain, to help define the measures needed to achieve the Sustainable Development Goals on food waste and share best practice and results achieved. 


\section{Food donation and redistribution in a context of social innovation}

\subsection{Baseline}

This section describes food waste drivers identified for the setting social innovation and food donation/redistribution and policy interventions that can address these drivers. The section starts with the description of a baseline situation, which presents the description of the current situation. The next section presents scenarios for this setting.

Before discussing the identified drivers of social innovation and donation and redistribution, it is important to emphasize the existing link between drivers hampering donation and redistribution activities and drivers hampering social innovation activities.

Specifically, social innovation, in the context of food waste prevention, is closely linked to the same drivers which influence donation and redistribution activities. Basically, in most examples of the social innovation, there should be a donor and a recipient of food that may otherwise have gone to waste; and the relationship between them, in whatever form, is where the social innovation occurs. However, smoothly running donation activities and assuring a reliable supply of surplus food are major preconditions to establish these socially innovative relationships; all these actors involved in social innovation activities are affected by a set of drivers (discussed in the previous section for food donation and redistribution activities), which indirectly influence the potential for successful social innovation activities.

Donors are the source of the surplus food which is made available for redistribution or use in a social innovation activity. Donors can be either commercial/corporate entities such as manufacturers, distributors, retailers, hospitality and food services companies or they can be consumers.

Commercial/corporate donors donate surplus product/stock/unsold or unused food/food close to or past its best before date but still edible and safe.

Consumer donors donate food not required at home/past best before date but still edible and safe.

Recipients are the onward processors, distributors or users of donated food. These include both charities who redistribute cooked or uncooked food to end users (consumers) or they can be individuals who receive cooked or uncooked food for their own consumption.

Charity recipients receive donated food for redistribution (for example dry/tinned ingredients, cereals, cold ready meals) or used in preparation of meals, (see example of FUSIONS Feasibility study Disco soup/ Bôcô at http://eu-fusions.org/index.php/social-innovations )

Individual recipients receive donated food for individual personal consumption, for example, via a social supermarket.

The relationship between donors and recipients can be a standard redistributive model, where stakeholders do not even meet (as with food banks) or more direct and 'unusual' in which social innovation plays an important role (as social supermarkets). For this direct and 'unusual' model, the involvement of the third actor, namely, social entrepreneur/innovator, is needed. The Social Entrepreneur/Innovator establishes a socially innovative activity in order to redistribute surplus food to needy recipients so to prevent waste and increase social justice and welfare.

Drivers and policy measures related to social innovation

It should be further stressed that, for social innovation initiatives based around redistribution, a reliable supply of surplus food is vital. Redistribution charities report that inconsistent sources and types of food donated to them make planning difficult and time consuming, cause instability for the recipients and put strain on the network infrastructure for the redistributors.

Incentives intended for the donor may encourage further donation but without investment in the network required to utilise additional donations, the food has no purpose.

The main drivers and policy measures specifically related to the deployment of social innovation include:

FUSIONS - Scenario analysis on current trends of food waste generation | 24 
Lack of funding: it is the most important driver raised by project managers delivering the FUSIONS feasibility projects and those consulted through the FUSIONS regional platform meetings across the EU. Social innovation relies, principally, on donations and volunteer time. However, there are often costs associated with the transport, storage, heating or cooling of food.

For example, HFA's HORECA food redistribution project - one of FUSIONS feasibility study- was able to secure a small amount of localised funding to pay for a project manager and some consumable items, but this funding was temporary and, without a revenue source, HFA would have to find alternative funding to continue the project. The UK's Community Shop suggests that around $£ 200,000(€ 255,000)$ are needed to set up a social supermarket. Running costs can be in the order of $€ 12,000$ to $€ 14,000$ per week (including payment for the food, and running an advanced personal development programme, which may not be necessary in other cases). According to Leinbacher and Holweg ${ }^{5}$, the average revenue of a social supermarket is $€ 46,000$ per annum.

Lack of education: where food waste is not a current curriculum topic in most Member States, there are no funds available to develop engaging materials which inform and educate children on the topic. As shown in the Cr-EAT-ive feasibility study, the project does not have the capacity to generate income and therefore is not economically self-sustainable without external funding.

Therefore policies which could be undertaken at EU level to address these drivers are:

- Establish pan-European as well national and regional funding programmes for projects using social innovation as a method of food waste prevention.

- Encourage or mandate the inclusion of food waste prevention as part of school curriculum or extra-curricular activity and provide funding to charities to deliver localised engagement activity.

A limited supply of volunteers and social innovators to establish social innovation activities (collecting food surplus): food surplus can often not be transported far from its source in an economic way and so several local projects and volunteers are required to undertake appropriate prevention activities. Availability of volunteers can be less predictable than salaried staff and charities often face difficulty in recruiting and retaining volunteers.

Consumer donors awareness: consumer donors may have concerns over liability or food safety if they donate food. Consumer donors may also lack awareness on activities such as Disco Soup /Bôcô and may also lack understanding of date labels leading to wasteful behaviours. Greater consumer awareness of the wider social and environmental implications of food waste may encourage greater participation in redistribution and donation activities.

Limited numbers of willing recipients of social innovation activity: food banks have proven to be popular but social supermarkets have encountered some reluctance among users due to social stigma (FUSIONS D4.3 Evaluation of Feasibility Studies). They may feel embarrassed or reluctant to receive or participate in redistribution and social innovation activities.

Awareness of charity recipients: Charity recipients may have concerns over liability / food near expiry/best before date but still edible/safe. For example in Austria, some social supermarkets inform their customers about the fact that some of the offered products could already have passed their best before dates, that the cooling chain may have been interrupted, and require the clients to sign that they are responsible for checking the products and consuming within a short timescale.

Furthermore, charity recipients may also have a lack of awareness and knowledge (for example, over labelling).

Practical steps that could be taken at EU level includes:

- To fund EU-wide campaigns to raise awareness on the issue of food waste, so to promote the donation of food and to encourage participation in social innovation activities (volunteering, etc.). Better informed citizens are more able to participate safely in redistribution, community cooking and other social innovation activities by assessing usefulness of food, designing recipes, evaluating safety etc;

5 Leinbacher \& Holweg (2010), Studie der Sozialmärkte in Österreich. Vienna: ECR-Workgroup on Social Sustainability and GS1. 
- To provide guidance, clarity and consistent application of legislation so to help consumers (individual recipients), charities and social entrepreneurs / innovators feel more confident and informed when donating food or participating in social innovation activities.

A limited number of social entrepreneurs/innovators and lack of practical information: potential social entrepreneurs/innovators should be aware of the issues of food waste and food poverty, have a reliable source of donated surplus food, volunteers, recipients to receive redistributed food and enough funding to establish their activity.

Guidance, clarity and consistent application of legislation would help them to feel more confident and informed when donating food or promoting social innovation activities.

Lack of supportive policy and legislative environment for food donation and redistribution activities: these drivers and the related policies are relevant for all actors involved in social innovation activities, as described below. Useful policy instruments in this case could be financial incentives for establishing socially innovative activities and for the donation of surplus food, especially from commercial sources which can provide a reliable volume and regularity of supply.

Drivers and policy measures related to food donation and redistribution activities

At present, only few data are available on the amounts of food donated and redistributed through social organisations such as food banks, social supermarkets and others (Schmied, 2003; Alexander and Smaje, 2008; Novotny, 2011; Scherhaufer and Schneider, 2011; Schneider, 2013). It should be noted that these published data only show a small piece of the action and should not be applied to regions or countries.

The lack of data is mainly explained by the fact that a huge number of charities operate at small, medium and large scale level and there is no official obligation to report such data in a harmonised way. Most charities have already implemented internal reporting systems but they are not willing to share their data. Furthermore, these data rely on rough estimations and do not fulfil reliability criteria. Also, different units are often used for estimation of amounts of donated and redistributed food (e.g. number of pallets, mass units, volume, number of packages, number of truck loads etc.). Therefore, at present, it is not possible to precisely estimate the current impact of food donation and redistribution in EU-28 in terms of mass food waste prevention and reduction (FUSIONS Food waste data set for EU28, 2015).

Food donation activities require the consideration of a rather complex system of current internal drivers (many are related to current government policies) affecting food donation activities. This work highlights the important elements of these drivers that could represent prerequisites for successful food donation and redistribution activities.

For the identified food waste drivers (specifically hampering food donation and redistribution activities), it is analysed how these drivers affect (cause/generate) food waste, how the driver can be addressed by a government policy measure, what type of policy measure can be designed and how it will address food waste reduction.

On the basis of the whole list of food waste drivers, three groups of drivers specifically related to the "food donation and redistribution activities" were identified:

1. Group 1: Lack of economic incentives to donate;

2. Group 2: Food safety, liability issues and labelling for food durability;

3. Group 3: Redistribution capacity and costs.

Each of these three categories contains a set of drivers explained below.

\section{Group 1: Lack of economic incentives to donate} Lack of (fiscal) incentives to donate surplus food

According to the VAT Council Directive 2006/112/EC14, food donations are taxable in the EU. Namely, VAT has to be paid on food intended for donation (Article 16). However, the taxable amount is the purchase price of the donated goods at the moment of the donation adjusted to the state of those goods at the time when the donation takes place (Article 74). In interpreting this legislation there is substantial uncertainty across MS as to the intended commercial value of food nearing its expiry date. In FUSIONS D.3.1 Vittuari et al. (2015) highlight that a legislation on harmonisation of VAT rules throughout the EU Member States e.g. by a VAT exemption for donated food could have a positive impact on donation and redistribution activities. Such a potential legislation is still discussed controversially. Schneider (2013) pointed out that opponents of such legislation claim that the same legal requirements should be applied for everyone who markets foodstuff, no matter who the beneficiary is. 
Lack of positive financial incentives: the removal of structural economic disincentives together with the provision of new economic incentives can encourage food donation and distribution and thus contribute to food waste reduction. In particular, various market-based policy instruments could be designed to incentivise donation activities ${ }^{6}$ like tax breaks, including any tax exemption (specific example of VAT is discussed above), tax deduction, or tax credit on a certain level of the value of donated food.

Food service establishments can receive tax benefits from donating wholesome, edible food to food banks or food rescue organizations. For example, $60 \%$ and $35 \%$ of the value of donated food, in France and Spain respectively, can be claimed as a corporate tax credit, meaning that food donors are able to deduct that percentage of the value of the donated food from the corporate tax on their revenue. Furthermore governments can support the implementation of voluntary agreements among food chain operators stimulating food waste prevention and reduction: adopting new certification schemes (mandatory or voluntary) that include special requirements for donation and (re)-distribution activities could be beneficial.

In certain circumstances, EU legislation provides financial support for food redistribution and donation activities:

- Fruit and vegetable growers can receive EU funding for disposing of produce which has been removed from the market as part of crisis management during periodic crises ${ }^{7}$. In this case, free redistribution and donation to charities and select institutions (e.g. hospitals, schools, etc.) is funded more generously than other forms of disposal. Indeed, while other uses are funded at around $50 \%$ or $60 \%$, the EU funds $100 \%$ of free redistribution, for quantities up to $5 \%$ of the producer's total marketed volume. The funding includes compensation for the product, as well logistical costs. This practice incentives food donation of produce by growers in specific circumstances.

- The recently-approved new Fund for European Aid to the Most Deprived (FEAD), following up on its predecessor FEAD, aims to financially support MS social emergency relief schemes. The $€ 3.8$ billion Fund will help finance MS actions which provide - free of charge - non-material financial assistance, including food, to the neediest populations. The Fund may therefore help food donation more economically viable. However, it is important to mention that currently almost $100 \%$ of this budget is spent on buying (newly produced) food on the market not effecting at all the problem of food waste - although the FEAD legislation promotes and allows it. For more background, the Regulation EU No 223/2014 of the European Parliament and of the Council ${ }^{8}$ can be used as reference. So, using or stimulating using at least part of FEAD sources/sources for redistribution activities could give a very strong boost to it.

Some Member States introduce own government policies to stimulate new forms of redistribution and of donation activities. The specific design of such own governmental policies still need to be further examined and elaborated. The first attempts to introduce policies more explicitly addressing donation and redistribution activities haven't been successful yet. For example, in late May 2015, French legislation was freshly adopted by the National Assembly on the reported obligation for supermarkets to donate edible and unsold food to relevant charitable organisations in order to reduce food waste. According to the law, supermarkets that have a surface area of at least $400 \mathrm{~m}^{2}$ are obliged to manage their unsold food within one or several of the four recovery options outlined within the legislation, depending on food quality. The law was, however, rejected due to some constitutional problems. It has been later suggested as a part of the "Energy transition" law as amendment, but still didn't go

\footnotetext{
${ }^{6}$ For an overview of market-based instruments with regard to food waste prevention and reduction please see the report: D3.3a: Market-based instruments and other socio-economic incentives enhancing food waste prevention and reduction (http://www.eu-fusions.org/index.php/publications.

7 More information can be found here: http://ec.europa.eu/agriculture/fruit-and-vegetables/freedistribution/index en.htm

8 Member States and beneficiaries shall choose the food and/or the basic material assistance on the basis of objective criteria related to the needs of the most deprived persons. The selection criteria for the food products, and where appropriate for goods, shall also take into consideration climatic and environmental aspects, in particular with a view to reduction of food waste."

"With the view to augmenting and diversifying the supply of food for the most deprived persons, as well as reducing and preventing food wastage, the Fund may support activities related to the collection, transport, storage and distribution of food donations."
} 
through. After the law was rejected, the Minister has proposed to change it to a voluntary agreement to retailers, but retailers were not happy, not as being obliged or voluntary. Retailers think that they do already a good job in donation and do not need any obligation; since among others, this may require different logistics etc. Also, in Romania, a very draft version of the similar law has been introduced recently to a parliament.

Low disposal costs: according to the Waste Framework Directive 2008/98/EC ${ }^{9}$, MS shall apply as a priority order the following waste management hierarchy: prevention, preparing for re-use, recycling, recovery and disposal. Although in principle such a food waste hierarchy prioritises food donation and redistribution, in practice, it is still more expensive in many MS, including the UK, to donate surplus food than to send it to AD. At present, there is no mechanism to enforce the proper implementation of the EU waste hierarchy in MS waste management legislation (BIO, 2014). Low costs for discarding food may encourage segments to discard food instead of donating, which is often related with more efforts and potential costs of VAT on food donation and associated liability risks.

Policy measures that could address this driver are:

- The development and publishing of a EU guidance on a food use hierarchy that clearly prioritises feeding humans, through food waste prevention and donation to charities over waste management options such as composting, anaerobic digestion and landfilling. This hierarchy would provide further clarification on the existing EU waste hierarchy in the context of food and send a clear signal to businesses and governments that economic incentives, investment in infrastructure, and communication activities should prioritise food redistribution (BIO,2014);

- The integration of the principles of the food use hierarchy into National Waste Prevention Programmes of Member States (BIO, 2014);

- The issue of legislation to promote diversion from landfill and the setting of stricter targets for reducing amounts of biodegradable waste in landfill and/or raising landfill taxes. See also Aramyan et al. 2016, for a complete overview of market-based policies potentially applicable to address this issue.

- The introduction of PAYT schemes (weight and frequency based schemes) so that in order to pay less, consumers and other actors in the supply chain will reduce food waste and implement food waste prevention and reduction measures. In this way, these schemes should also stimulate the use of food in alternative ways (e.g. donation);

- The introduction of taxes (incineration and landfill taxes, landfill tax credit scheme).

\section{Group 2: Food safety, liability and labelling food durability}

No specific existing EU legislation is explicitly dedicated to food donation activities. However, next to the VAT directive described above, several different pieces of legislation influence food donation activities, mainly by creating barriers to donation activities.

The EU General Food Law ${ }^{10}$ is also one of these pieces. The EU General Food Law lays out the fundamental framework for EU food legislation, including definitions and principles for all stages of food production and distribution. According to Article 3.8 of the General Food Law, food donation falls under "placing on the market" operations (i.e. sale or other transfer of food), which means that donated food must comply with the same food legislation and rules as sold food. This legislation forms the basis of all the other legislations regarding food donation and redistribution.

The General Food Law addresses safety of donated food, stipulating that "it is unacceptable to donate food which is dangerous, i.e. harmful to health or unfit for human consumption" (Article 14). It also establishes the responsibility of "food business operators" to ensure "that the requirements of food law are met within the food business under their control" (Article 17). "Food business operators" are defined as "the natural or legal persons responsible for ensuring that the requirements of food law are met within the food business under their control". These include food banks and others involved in food donation, conferring on them the responsibility for food safety and traceability during the

\footnotetext{
${ }^{9}$ Directive 2008/98/EC http://eur-lex.europa.eu/legal-content/EN/TXT/?uri=CELEX:32008L0098

${ }^{10}$ Regulation (EC) No 178/2002 of the European Parliament and of the Council of 28 January 2002 laying down the general principles and requirements of food law, establishing the European Food Safety Authority and laying down procedures in matters of food safety.
} 
operations under their control. Food donors may be driven to discard surplus food instead of distributing it to food banks or charity organizations in order to avoid risks associated with liability for donated food.

The Food Hygiene Package Regulation (EC) No $852 / 204^{11}$ is another relevant piece of legislation. This Regulation is the main legislation on food hygiene and lays down general rules for food business operators (as defined under the General Food Law) on the hygiene of foodstuffs. Among other things, the Food Hygiene Package Regulation stipulates that primary responsibility for food safety rests with the food business operator and that it is necessary to ensure food safety throughout the food chain. As under the General Food Law, this responsibility also applies to food banks and others donating food. However, as it has been shown by BIO by Delloitte (2014) ${ }^{12}$, some Member States can interpret the EU Hygiene Package rigidly (especially rules related to food safety, storage and transport), creating more difficult conditions for food donation. Furthermore, there are no EU guidelines designed for food business operators clarifying their compliance with the EU Food Hygiene legislation when donating food.

So, both the General Food Law and the Food Hygiene Package Regulation, similar to the VAT Council Directive 2006/112/EC14, provide disincentive to donate. Thus, a common dedicated EU policy framework to reduce regulatory burdens to donation activities could also be considered here as a potential government policy to reduce effect of these drivers on wood waste. Proposed policy measures include the revision of the General Food Law principals, by limiting donor liability on food that meets quality and labelling standards imposed by legislation, the development of industry-charity good practice guidelines along with a clear, harmonised traceability system to assure the required level of food safety and the clarification of EU hygiene legislation with respect to donation activities, and responsibilities of retailers and food banks

Food donation liability legislation. According to Article 9 of the Regulation (EC) No $1169 / 2011^{13}$ on the provision of food information to consumers, food business operators are required to determine, based on the composition of the product, whether it is appropriate to use a 'best before' or a 'use by' date. Products past their 'use by' date are not marketable and thus cannot be donated; whereas products past their 'best before' date can still be donated if the product was properly stored. There is a general misunderstanding and confusion across the EU about the potential to donate food that has passed its 'best before' date. There is a further concern that food donated after its 'best before' date may be of inferior quality and that the deprived benefiting from donated food should not receive inferior products (BIO, 2014). Also, the situation with potential donation of the food close to its "use by" date is not very clear, since the "use by" date implies potential food safety risk; which is associated with the issue of liability, involving substantial cost in case of food safety failure. Ultimately, all these uncertainties raise potential liability issues related to donated food.

In this sense, government policies that exempt food donors from legal liability for donated food might provide a substantial incentive for food donation. Several MS have already allowed companies to consider the value of donated food as zero or close to zero at point of donation. Others use alternative mechanisms to allow for a VAT exemption for donated food in their national law. For a more detailed comparison of tax legislation on taxation of food donation, this work refers to BIO (2014). Italy is a frontrunner in food donation liability legislation, being the first EU country to have passed the Good Samaritan Law (La Legge del Buon Samaritano), similar to the US the Bill Emerson Good Samaritan Food Donation Act from US. ${ }^{14}$ Thus it would be good if a EU-wide Good Samaritan Law would be

${ }^{11}$ Regulation (EC) No 852/2004 of the European Parliament and of the Council of 29 April 2004 on the hygiene of foodstuffs

12 http://www.eesc.europa.eu/?i=portal.en.events-and-activities-eu-food-donations

${ }^{13}$ Regulation (EC) No 1169/2011

http://eur-lex.europa.eu/LexUriServ/LexUriServ.do?uri=OJ:L:2011:304:0018:0063:EN:PDF

${ }^{14}$ In 2003, with the aim of fostering food donation, the Italian Parliament passed Law No. 155/20031 following the example provided by the US Good Samaritan Act (1996). In the USA, the Act protects food donors and non-profit charitable organizations recovering and distributing surplus food from civil and criminal liability should the product donated in good faith later cause harm to the recipient. According to Law No. 155/2003, the O.N.L.U.S. (Organizzazioni non Lucrative di Utilità Sociale), non-profit organizations that carry out their activity for purposes of charity) are considered as "final consumers" for what it relates to liability and responsibility arising from food safety rules. Law No.155/2003 predates the Hygiene Package and was based on the following rationale: 
passed to protect food donors from civil or criminal liability, if a list of products that could be exempted from the requirement for a 'best before' date could be provided (extension of Annex X of EU Regulation 1169/2011) (BIO, 2014) and EU guidance provided to assess additional lifetimes of products after their initial (producer indicated) date of minimum durability ('best before' date) has passed (e.g. based on the Belgian model (BIO, 2014).

Labelling food durability: food with mismarked/mislabelled packaging is a common source for food donations since this safe and edible food cannot be sold due to unintended label issues (e.g. due to size of the labelling text, sugar content labelling, allergen labelling). Relabelling is however required to be able to redistribute such donated food. The labelling rules vary significantly between countries. Food products wrongly labelled (that is not exactly according to the requirements of the importer, e.g. wrong size of the labelling text) have to be scrapped while stopped at the border.

An adjustment of the (re-)labelling policy for donated food. (e.g., labelling only the secondary packaging instead of labelling each individual product, in case of donating whole packages to final recipients) could be beneficial.

\section{Group 3: Redistribution capacity and costs}

Next to these two main groups of drivers (lack of economic incentives and food safety, liability issues and labelling for food durability) that might be addressed by government policies, there are two major obstacles related to recipients and to donor-recipient relationships. These are immature infrastructure and the associated costs of redistribution. The charity organisations need to cover their costs somehow in order to be able to donate. Some studies indicate that there are limits which should be considered while planning redistribution policies and strategies. Schneider (2011) discusses the local market saturation in Austria for redistributed food products such as waste bread (Schneider and Wassermann, 2004 and Scherhaufer and Schneider, 2011). Also, Lienbacher and Holweg (2011) identified the need to establish a limit with respect to the number of Austrian social supermarkets related to public subsidies and corresponding economic survival. This fact indicates the need to balance the regional offer of available products, demand for products and increased effort for redistribution logistics. This implies that, a new EU policy framework should take into consideration the capacities of charities and also the quality of donated surplus food. Otherwise, the waste management is only displaced from business to charity and fails the aim of food waste prevention. The emphasis on addressing the immature infrastructure has been strongly made during the consultation sessions with experts in FUSIONS RPMs.

Based on the drivers hampering food donation/redistribution activities described above a system map has been developed( see Fig 4.1). The system map below presents the current situation of the drivers hampering food waste donation and redistribution and policies that can address these drivers.

- O.N.L.U.S., as Food Banks, due to their special nature are considered as final consumers.

- The law fosters food donation as the donors are only liable towards the recipients of the food (i.e. Food Banks or other O.N.L.U.S.), which are considered as final consumers. Therefore, ordinary product liability rules as set by Directive 85/374/EEC and by national tort law do not apply to donated food. 


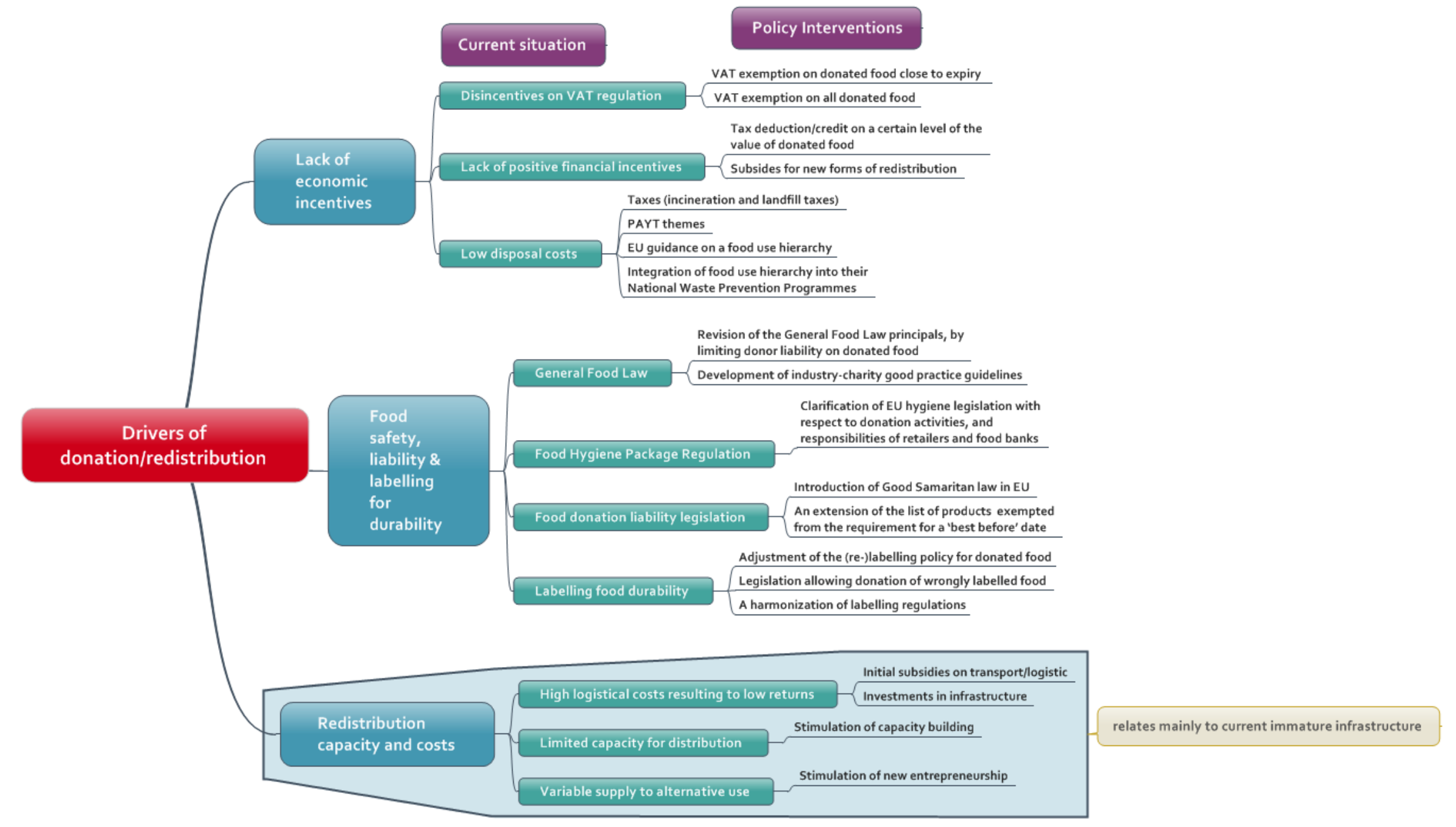

Figure 4.1 System map: food donation and redistribution

FUSIONS - Scenario analysis on current trends of food waste generation | 31 


\subsection{Social innovation and food redistribution activities}

From Figure 4.1 it is possible to identify three major groups of food waste drivers and related policies hampering food donation/distribution possibilities, thus reduction of food waste. The first two, lack of economic incentives and food safety and liability issues, are mainly related to the donor side. The third category of drivers, redistribution capacity and costs, is more related to the recipient side and donor-recipient relationships. The present scenario analyses focuses on these three major aspects. The time horizon is set up to 2030, based on the timeline of the SDG goals. The food supply chain stakeholders involved are manufacturers, processing industries, wholesalers and retailers.

\section{Scenario: Business as usual (BaU)}

This scenario implies a slight but steady food waste reduction. No significant changes in the food waste policy with respect to the present day situation. The BaU scenario reflects a future in which major socio-economic drivers follow current trends and assumes that there are no major policy changes. This scenario assumes continued implementation of current policies impacting food waste such as:

- Lack of economic incentives;

- Food safety, liability and food durability labelling issues.

\section{Narrative}

No significant changes in policies related to food donation with respect to the present day situation. The BaU scenario reflects a future in which major socio-economic drivers follow current trends and assumes that there are no major policy changes. It assumes decreasing population growth in Europa. GDP growth per capita will remain roughly constant. Urbanization level will remain moderate. Food consumption per capita will slightly increase, with expectations of limited red meat consumption while poultry consumption grows modestly. Fruits and vegetables are expected to become an increasing share of the diet, thus will contribute to more food waste generation (i.e. fresh perishable products). Consumer preferences will remain the same with expectations for 'perfect' products and possibility to buy all types of food all year round (mostly fresh fruits and vegetables). Consumers will continue to choose products with the longest shelf life. Volatility of food prices will continue, which may result in decreasing of food waste generation especially during the global recession and financial crisis, however after the financial crisis, with the return toward long-run steady growth, this trend may have decreasing effect on food waste reduction. Increasing global sourcing and concentration will continue, contributing to food waste generation.

This scenario assumes a slight but steadily decrease of food waste. This is possible as a result of the following trends:

- Increased awareness in the society about food waste and its implications;

- National objectives to reduce food waste in certain MS;

- Ongoing awareness campaigns, initiatives in the sector and social organizations (also involved in food donation and redistribution activities- see for instance the guidelines prepared by FoodDrinkEurope, EuroCommerce and the European Federation of Food Banks - FEBA) ${ }^{15}$ );

- Take off of food waste prevention (efficient) technologies.

Under the BaU scenario levels of food donation will remain variable across MS, as no common dedicated framework exists at EU level, and as variations remain in interpretation and implementation of certain legislation, such as VAT or food hygiene legislation. Those MS that have already implemented/adjusted the law related to VAT tax (UK, Germany, France, Italy have already zero VAT) may continue their activities in donation in a steady pace as it is now: food donation will mainly depend on private initiatives (e.g. the above mentioned new guidelines launched by FEBA (European

\footnotetext{
${ }^{15}$ These guidelines have been prepared jointly by setting out a simple framework of practical steps that can be taken aiming to help food and drink manufacturers, retailers and wholesalers anticipate and prepare for

any potential surplus that may arise in the business. http://www.fooddrinkeurope.eu/uploads/publications documents/Every Meal Matters Food Donation Guidelines.p $\underline{\mathrm{df}}$
} 
Federation of Food Banks), FoodDrinkEurope and EuroCommerce to encourage and make it easier for food manufacturers and retailers to donate their food surpluses to food banks). However other disincentives such as low costs of disposal, lack of positive financial incentives such as not harmonised tax deduction across MS countries, on donated food and/or liability issues will still hamper food donation, thus waste prevention and reduction activities. Similarly policies related to food safety and responsibilities regarding liabilities of donated food such as the General food law on donated food will remain unchanged and the Good Samaritan Law will continue its activities in countries where it already exists (Italy). Food donation may grow in line with decrease in waste generation due to already working initiatives, and eventually also due to local/national or private efforts, particularly in times of economic hardship or crisis. However, it would not grow as significantly as it could, given a supportive legislative framework.

Pros
No costs involved for the EU to create new legislation
(or adjust existing legislation) and/or provide guidance
on implementation.
on implementation.

\begin{abstract}
Cons
Food waste generation will continue decreasing but with slow pace given that expected socioeconomic trends will contribute to waste generation, but will be balanced by already existing initiatives;

Without incentives or removed barriers, food donation/redistribution will not grow as much as it could under dedicated supportive legislation;

With remaining uncertainties in laws' interpretation, willing stakeholders may be hesitant to engage in food donation/redistribution;

The persistent missed opportunity to use food wasted for other purposes will lead to unchanged environmental social and nutritional impacts.
\end{abstract}

\section{Scenario: Supportive legislation}

This scenario assumes that policies will be adjusted/changed and will favour mainly food waste reduction through increasing food donation/redistribution activities when the regulations hampering food donation/redistribution will be fully addressed.

The target is primarily the greatest possible food waste reduction through changes in current legislations, while other economic concerns can be limited. In this scenario we assume that the immature infrastructure of redistribution will be developed by businesses and market forces, obliged to do so by new regulations.

\section{Narrative}

Following the recommendations suggested and described in the baseline situation, when it comes to food donation, a common dedicated EU framework could be created to incentivise redistribution activities. In the best-case scenario, which aims to reduce food waste mainly through changes in legislations related to donation/redistribution, food donation activities could be maximised by removing key barriers and providing additional incentives. Specifically:

1) Lack of economic incentives will be addressed by creating incentives:

- VAT exemption would be provided on donated food, or a stipulation would be added to EU VAT law stating that donated food nearing its expiry date has a commercial value equal to zero.

- Financial incentives such as tax deduction, or tax credit on a certain level of the value of donated food. would be expanded and harmonized across the EU MS to encourage donation of unused food by specific stakeholders across the value chain.

- Legislations addressing low costs of disposal such as the promotion of diversion from landfill would be strengthened - setting stricter targets for reducing amounts of biodegradable waste in landfill and/or raising landfill taxes and/or PAYT themes to provide disincentives to landfilling and make donation a relatively more attractive option.

2) Food safety and liability issues will be addressed:

- An EU-wide Good Samaritan Law would be passed to protect food donors from civil or criminal liability.

- Food general law and EU hygiene legislation would be clarified with respect to donation activities, plus responsibilities of retailers and food banks would be made clear (without negatively impacting food safety or quality) 
The socio-economic trends will remain the same as in the BaU scenario.

Pros available food;

Potential for jobs in the food donation and redistribution sector;

Lower waste management costs as less food goes to waste;

Financial gains for stakeholders across the food chain engaging in food donation;

Positive impact on household incomes for consumers benefitting from donation;

Potential positive impact on food safety as hygiene legislation is clarified and standardised.

Reduction of environmental impacts: $\mathrm{CO} 2$ emission when food remains in food chain instead of going to incineration, reducing disposal, opportunities for recycling.

\section{Cons}

Development and implementation of several pieces of new legislation - or modification of existing legislation may involve substantial costs for the EU and MS;

Very strong incentives for donation may cause actors to decrease other food waste prevention efforts (efforts to decrease food waste generation in the first place);-food hierarchy should be respected, the policy makers have to check/monitor it.

The entire package of legislation would be very difficult to pass (the scenario is very "best case").

There might be limited implementation without supportive infrastructure related to realisation of the surplus, logistics and capacity for redistribution.

Several preconditions should be met such as:

- Donation should be made earlier than expiration date (eg. also on maturity);

- Social organization should have freedom of choice in selecting the food they need.;

- Social organisations should be allowed to ask a small price to customers for handling costs of distribution or reprocessing (eg. meals).

The feasibility of these policies is however questionable in terms of:

- Organisational feasibility;

- Cost consequences: also because some of the current economic/fiscal disincentives are a substantial source of MS-national budgets.

III. Scenario: Supportive infrastructure

This scenario implies food waste reduction through moderate policy interventions in food donation/redistribution activities.

This scenario assumes that further policies will be implemented to support food donation/redistribution activities that will be mainly directed to the immature infrastructure with a strong focus on capacity building activities and engaging business sector by using different market based instruments/incentives.

\section{Narrative}

Taking into account the difficulty and costs of creating and implementing new dedicated legislations, this scenario will focus on implementation of supportive policies with a strong focus on the relationships between donors and recipients, capacity building activities and engaging business sector using different market based instruments/incentives and clarification of the existing policies related to donation /redistribution. The socio-economic trends will remain the same as in the BaU scenario. Specifically:

- Financial incentives at EU level would be strengthened to provide support for specific donation activities e.g. tax deduction;

- Stimulation of entrepreneurship by:

- Providing funds for starting entrepreneurs with new business models (example of the gleaning activities and social innovation initiatives);

- Providing low-interest financing on business stimulating food donation/redistribution activities;

- Guaranteeing lower risk (insurance-wise) for starters;

- Capacity building activities directed to:

- Developing good partnerships for food donation - for example, sharing collaborative model: municipality- social organizations- supermarkets -farmers;

- trainings for social organizations; 
- To introduce matching funds-private public partnership to build/develop infrastructure for new business models (e.g. to address logistics problems and dal with available capacity of surplus food);

- Sharing/promoting best practices: Last Minute Market (Italy) and BOROUME (Greece), 2 organizations working in the field of food recovery, have shown how to reduce the operational cost of food donations by developing innovative models thus bringing social benefits (for socially underprivileged people), environmental benefits (a reduction in food waste disposal) and economic benefits (for retailers which donate food instead of throwing it away and charities).

- EU VAT policy would be clarified with regards to donated food nearing its expiry date. Rather than setting the commercial value of such products to zero, it could be clarified within the VAT Directive that MS have the freedom to interpret the law as meaning that these products either maintain a non-zero commercial value or that their value is close to or equal to zero. The EU may provide recommendations that the assigned value be close to zero.

- EU food hygiene legislation would be clarified, particularly with regards to the possibility to donate food which has reached its "best before" date. The responsibility of both retailers and food banks involved in donation would be presented more clearly (without compromising food safety).

\section{Pros \\ Social benefits as more people are provided access to available food;}

Potential for jobs in the food donation and redistribution sector;

Lower waste management costs as less food goes to waste;

Financial gains for stakeholders across the food chain engaging in food donation;

Positive impact on household incomes for consumers benefitting from donation;

Potential positive impact on food safety as hygiene legislation is clarified and standardised;

Reduction of environmental impacts: $\mathrm{CO} 2$ emission when food remains in food chain instead of going to incineration, reducing disposal, opportunities for recycling;

New business opportunities from selling food via alternative channels and job creation opportunities;

Redistribution of surpluses will help charities to provide healthier and more varied diets for vulnerable people within communities.

\section{Cons}

Creating and disseminating clarifications would imply costs for EU and MS

Developing financial incentives or funding would imply direct major costs for EU or MS budgets;

Logistics (e.g empty loads moving around)

Several preconditions should be met such as:

- Donation should be made earlier than expiration date (eg. also on maturity);

- Social organization should have freedom of choice in terms of selection of donated food.

- Products are made ready (eg. frozen in) by the SM itself;

- Permit social organisations to ask a small price to customers for better managing the handling costs of distribution or reprocessing (eg. meals);

- Transparency in procedures (different for each supply chain).

Table 4.1 Summary: food donation and redistribution

\begin{tabular}{|l|l|} 
Business as usual & $\begin{array}{l}\text { No significant changes in the food waste policy with respect to the present day situation. } \\
\text { The BaU scenario reflects a future in which major socio-economic drivers follow current } \\
\text { trends and assumes that there are no major policy changes. }\end{array}$ \\
\hline $\begin{array}{l}\text { Supportive } \\
\text { legislation }\end{array}$ & $\begin{array}{l}\text { This scenario assumes that further policies will be implemented to support food } \\
\text { donation/redistribution activities with a strong focus on policies implementations } \\
\text { directed to changes in current legislations hampering food } \\
\text { donation/redistribution. In this case we assume that the required infrastructure to } \\
\text { facilitate donation/redistribution(e.g. logistics, capacity, supply and demand) will be } \\
\text { developed by businesses and market forces if they are obliged to adopt new regulations. }\end{array}$
\end{tabular}


Supportive infrastructure
This scenario assumes that further policies will be implemented to support food donation/redistribution activities with a strong focus on building infrastructure to facilitate donation/redistribution by means of capacity building activities and engaging business sector using different market based instruments/incentives. 


\section{A multi-target approach towards reducing food waste in EU-28}

This sections aims to provide the current trends of food waste generation and to develop a baseline situation of food waste in the EU-28 building on the inventory and selection of food waste drivers identified by previous work in FUSIONS ${ }^{16}$ and policies addressing these drivers (inputs from D3.1; D3.2, D3.3 of the FUSIONS project).

\subsection{Baseline}

According to the most recent assessment of food waste level published by the FUSIONS consortium, Europe generates an estimate of 88 million tonnes of food waste in the EU-28 ${ }^{17}$. This estimate, calculated by using data from 2012, includes both edible food and inedible food parts (such as orange peels). The total amount of food produced in EU for 2011 was around 865 $\mathrm{kg} /$ person, meaning that the EU-28 wastes $20 \%$ of the total food produced while ironically 55 million Europeans are not able to afford a quality meal every two days ${ }^{18}$.

According to this same FUSIONS report, the sectors contributing the most to food waste, accounting to $72 \%$ of EU food waste are:

- Households: 47 million tonnes \pm 4 million tonnes

- Food processing ${ }^{19}: 17$ million tonnes \pm 13 million tonnes

The remaining $28 \%$ of EU food waste are generated from the following sectors:

- Food service: 11 million tonnes (12\%)

- Primary production: 9 million tonnes (10\%)

- Wholesale and retail: 5 million tonnes (5\%)

The financial cost of food waste for EU-28 in 2012 is estimated to be the equivalent of 143 billion euros. Accounting for about two thirds of EU-28's total food waste costs, the household sector's waste generation equates to approximately 98 billion euros.

Given its impacts, food waste is an integral part of the European and the global agenda.

The 2030 Agenda for Sustainable Development, adopted by the United Nations General Assembly on 25 September 2015 exemplifies a reach towards food waste reduction via the Sustainable Development Goal (SDG) 12.3 target to halve per capita global food waste at the retail and consumer levels and reduce food losses along production and supply chains, including post-harvest losses, by 2030.

The European Commission's Circular Economy Package adopted on December 2, 2015 calls on Member States to take several measures to promote prevention of food waste, and in particular to create a link to SDG 12.3 by integrating the target of halving food waste by 2030 within its text.

In order to support Member States' efforts in reaching the SDG 12.3 target, the Circular Economy Package includes a comprehensive Action Plan of several food waste related provisions:

- Elaboration of a common EU methodology to measure food waste consistently in cooperation with Member States and stakeholders;

- Creation of a new platform involving both Member States and actors in the food chain in order to help define measures needed to achieve the food waste SDG, facilitate inter-sector cooperation, and share best practice and results achieved;

\footnotetext{
${ }^{16}$ Canali et al., 2014, "Drivers of current food waste generation, threats of future increase and opportunities for reduction")

17 Stenmarck A. Jensen C. et all , Estimates for European food waste levels, March 2016

${ }^{18}$ Eurostat, October 2015

${ }_{19}$ There is considerable uncertainty around the estimate for the food processors sector compared to all the other sectors.
} 
- Clarification of EU legislation related to waste, food and feed and facilitation of food donation and the use of former foodstuffs and by-products from the food chain for feed production, without compromising food and feed safety;

- Examination of ways to improve the use of date marking by actors in the food chain and its understanding by consumers, in particular "best before" labelling.

The revised Directive 2008/98/EC on waste is currently being examined by the European Parliament where several amendments were proposed such as ${ }^{20}$ :

- The introduction of the $50 \%$ food waste reduction target in national waste prevention programmes established by Member States;

- The set-up of conventions enabling the food retail sector to distribute unsold products to charitable organisations.

Although over 150 food waste drivers have been identified via FUSIONS work, three main drivers have been selected to assess within this setting:

1. (lack of) food waste quantification across the food supply chain;

2. (confusion related to) date marking and food labelling;

3. (lack of guidance on) food waste valorisation solutions;

\section{Food waste quantification across the food supply chain}

FUSIONS research on EU-28 food waste levels, has illustrated that there is a relatively high uncertainty of the EU food waste estimate due to the fact that many data gaps still exist, despite the improved availability and quality of national food waste data. Data of sufficient quality only exist for up to a quarter of EU Member States rendering the existing data to the whole EU-28 quite uncertain.

FUSIONS extensive literature review ${ }^{21}$ has also shown that there is no common methodology to quantify food waste in the different Member States and at the different steps of the supply chain. Food waste quantification is however essential in order to get a better understanding of the magnitude and location of food waste hotspots within the food chain which may inform waste prevention measures. For example, the lack of understanding of the food waste magnitude creates irregular demands and improper forecasting. This could lead to higher percentage of wastage of those products which are offered despite negligible demand.

Food waste quantification and reporting facilitates can better define, prioritize and target prevention efforts, as well as track progress over time. In an effort to address this need, FUSIONS developed a food waste Quantification Manual 22 with the goal of supporting Member States in developing coherent methods for acquiring national food waste data covering all sectors of the food chain. On June 6 2016, the World Resource Institute published the Global Food Waste \& Loss Protocol ${ }^{23}$, a set of global definitions and reporting requirements for companies, countries and others to consistently and credibly measure, report on and manage food loss and waste.

\section{Date marking and food labelling}

It is estimated that a considerable share of household food waste $(15-33 \%)^{24}$ in the EU could be linked to consumer misunderstanding of date marking, for example interpretation of "best before" and "use by" dates are not common knowledge. According to a recent Eurobarometer survey ${ }^{25}$, $49 \%$ of Europeans think that better and clearer information on the meaning of "best before" and "use by" dates would help them waste less food at home. As at the household level, one third of the food waste is linked to date labelling on food products ${ }^{26}$, there is great potential to reduce food waste at the household level via more awareness raising or/and a simplification of date marking terminology.

20

http://www.europarl.europa.eu/sides/getDoc.do?pubRef=-//EP//NONSGML+COMPARL+PE-

$580.497+01+\mathrm{DOC}+\mathrm{PDF}+\mathrm{V} 0 / / \mathrm{EN} \&$ language $=\mathrm{EN}$

21 Östergren, K et all (2014) Report on review of (food) waste reporting methodology and practice 22

http://www.eu-

fusions.org/phocadownload/Publications/Food\%20waste $\% 20$ quantification $\% 20$ manual\%20to $\% 20$ monitor\%20fo od\%20waste\%20amounts\%20and\%20progression.pdf

23 http://www.wri.org/our-work/project/food-loss-waste-protocol

24 Note from the Netherlands and Sweden to the Agriculture Council of the European Union, May 2014;

${ }^{25} \mathrm{http}$ ://ec.europa.eu/food/safety/docs/fw_eu_actions_date_marking_infographic_en.pdf

${ }^{26}$ Eurobarometer, 2015 
While consumer understanding of date marking has been explored via surveys and other studies, there is still insufficient knowledge of how date labelling affects the other actors in the food chain. The key piece of EU legislation for date marking, Regulation (EU) No 1169/2011 on the provision of food to consumers states that the type and length of time of date marking are chosen by food business operators. Therefore, the private sector has also great potential to reduce food waste via better date marking methodology. Research has shown that food producers generally set the "best before" dates well before the product actually is not edible. The European Commission has for objective to look into extending the list of foods which are exempt from the obligation to include a "best before" date on their food labels, such as non-perishable products like flour or rice (as specified in Annex X of Regulation (EU) No 1169/2011).

Member States also have different national rules and practices regarding marking and redistribution of foods past the "best before" date. For example, although it is legal in most EU countries to sell or to donate products which have surpassed their "best before" date, there is a lack of guidance on how to manage these food products to ensure their optimal recovery. The European Commission is also currently looking into the modification of the terminology used for "best before" labelling, especially if there is evidence that alternate wording would be better understood and more useful to the consumer.

\section{Food waste valorisation solutions}

Any food, including inedible parts leaving the food supply chain, is considered as a secondary resource for further valorisation. Efforts to recover food surplus and waste are done via various outlets, such as food donation to those in need, anaerobic digestion or composting, etc. however there is still no evidence-based research on which outlet is the most cost-effective valorisation route. Regardless, some Member States have already created awareness about recovering food by applying the EU waste hierarchy (also known in literature as the EU "food use hierarchy"). The "food use" hierarchy prioritises actions food chain actors and Member States can take to prevent and divert food waste: prevention, food donation, animal feed (or industrial use), recovery (anaerobic digestion or composting) and disposal. This can notably be seen within France's national legislation, LOI $n^{\circ} 2016-138$ du 11 février 2016 relative à la lutte contre le gaspillage alimentaire 27 , which obliges supermarkets that have a surface area of at least $400 \mathrm{~m}^{2}$ to facilitate food waste reduction by establishing contracts with relevant charitable organisations to donate retailer food surplus. Via this obligation, the "food use hierarchy" prioritises food waste prevention and donation over animal feed, compost, and anaerobic digestion.

One of the key food waste drivers identified by FUSIONS 28 is the lack of food waste valorisation via animal feed. Research has shown that his stems from the poor understanding of the Animal ByProduct Regulation (EC) Nr 1774/2002 (ABP Regulation) by businesses. Introduced in the wake of the of the Bovine spongiform encephalopathy (BSE) crisis, the ABP Regulation is a comprehensive, directly applicable legal instrument, which clearly indicates what may or may not be done with any part of an animal or product of animal origin not intended for human consumption, ensuring its safety vis-à-vis animal and human health. The legislation was interpreted as an EU ban on using animal by-products in animal feed, facilitating food waste across the food supply chain (especially within the food processing of farm staples and food services sectors).

\footnotetext{
27 Journal Officiel de la France (2015). LOI no 2016-138 du 11 février 2016 relative à la lutte contre le gaspillage alimentaire (1) https://www.legifrance.gouv.fr/jo pdf.do?id=JORFTEXT000032036289

${ }^{28}$ Canali, 2014
} 


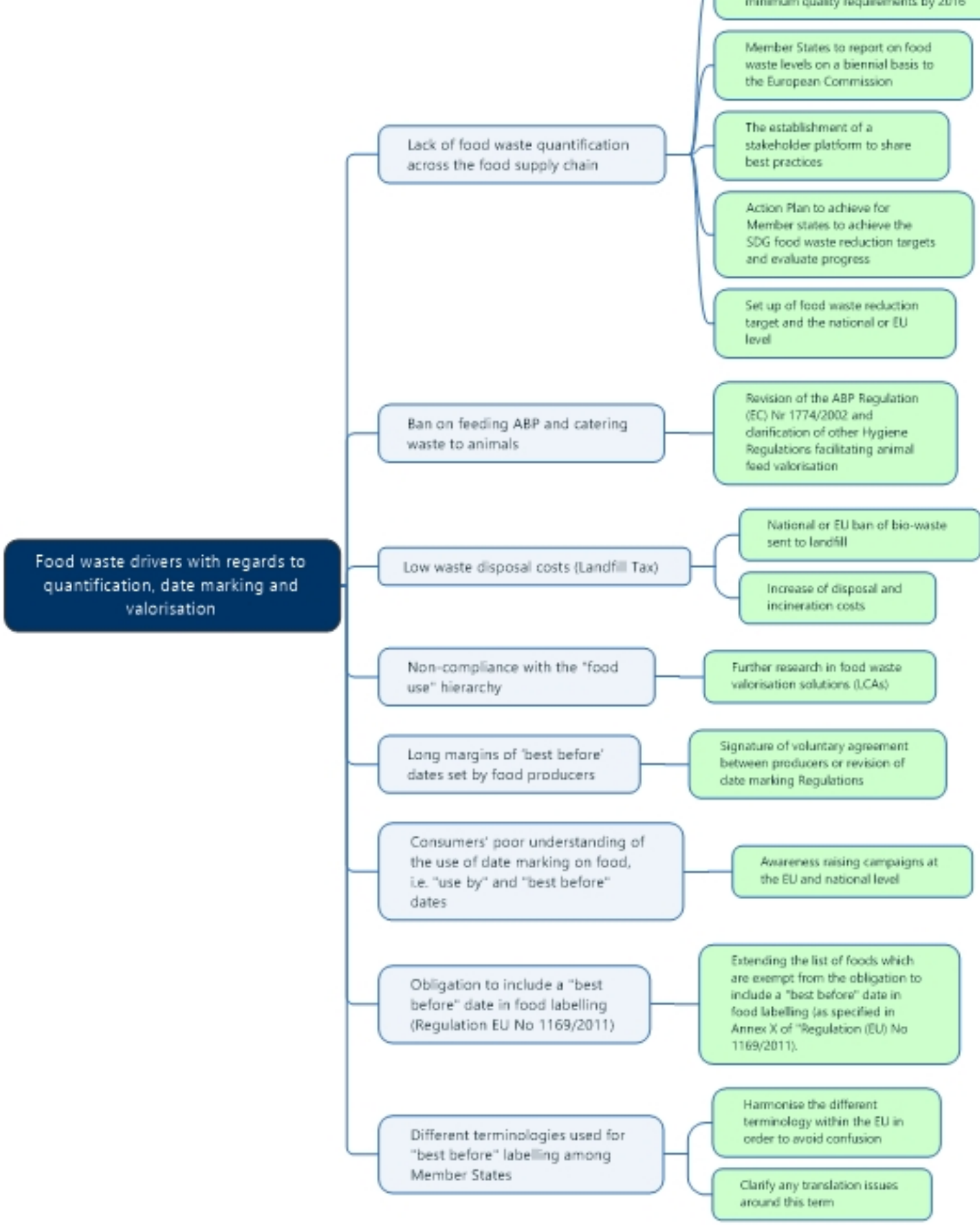

Figure 5.1 System map: multi-target approach towards reducing food waste in EU-28 


\subsection{A multi-target approach towards reducing food waste in EU-28}

Four scenarios are outlined within this setting:

- The Business as Usual scenario depicting a climate in which current day practices and policy measures are applied in the same fashion without changes to food waste policy;

- The "Increased food waste quantification in EU-28" scenario, which assumes that Member states and actors across the food chain increase their efforts in quantifying food waste

- The "Clarification and simplification of date marking" scenario, which assumes that there is a better understanding and use of date marking by all relevant actors, including food producers, consumers and national regulatory authorities;

- The "Guidance on valorisation solutions" scenario, which assumes that more sciencebased research will support food chain actors to recover food waste at the highest possible value.

\section{Scenario: Business as usual (BaU)}

The business as usual (BaU) scenario illustrates a climate much like present day, where major socioeconomic drivers follow current trends without the impact of major policy changes. This scenario would entail no drastic change to how current policies impact food waste in general.

\section{Narrative}

The following BaU scenario represents a depiction of current day policy implementation related to three main food waste drivers: food waste quantification across the food supply chain, date marking and food labelling, and food waste valorisation solutions. Major socio-economic drivers continue to follow current trends and the main drivers remain unaffected by major policy changes.

Within this scenario, the following could be foreseen:

- $\quad$ Food waste quantification across the food supply chain

Actors within the food supply chain would either continue quantifying their food waste via unharmonised methodologies, or would not quantify food waste at all. This uninform data reporting would further provoke data gaps (such as those highlighted in the food waste estimates developed by FUSIONS ${ }^{29}$ ), leading to continued low visibility of food waste hotspots and its magnitude on the local, national and EU level. Moreover, poor identification of the sectors and the steps (within the food chain) in which food waste is generated would persist. While food waste quantification could be enhanced via private and public initiatives, the lack of quantification homogeneity would continue to represent a barrier for data comparability.

Member States and the private sector would not take advantage of using a food waste quantification methodology (such as the FUSIONS Quantification Manual or the WRI's FLW Standard) and food waste data comparability would continue to be poor. If some countries would continue to lack food waste reduction targets, some may communicate on national food waste (reduction) levels. Furthermore, within a global context, there would be a continued disjoint between national food waste reduction efforts and the Sustainable Development Goal (SDGs) 12.3 global food waste reduction target. In the absence of a EU-wide legislation on food waste reduction, Member States would potentially establish their own food waste reduction targets at the national level. This is already the case in several EU Member states such as France and Scotland. Member State action would be driven by the projected revision of the Directive 2008/98/EC on waste. The reduction would introduce a $50 \%$ food waste reduction target in national waste prevention programmes established by Member States.

\section{- Date marking and food labelling}

Consumers would continue to misinterpret "best before" and "use by" dates. Food waste at the household level would still be linked to the lack of understanding of date marking. Furthermore,

29 Stenmarck,A. et all (2016), Estimates of European food waste levels, http://eufusions.org/phocadownload/Publications/Estimates $\% 20$ of $\% 20$ European $\% 20$ food $\% 20$ waste $\% 20$ levels.pdf 
producers would continue setting "best before" and "use by" dates on products well before they are no longer edible (in order to further minimise any health and safety issues). The first point could be considered as a consequence of low transparency and insufficient communication aimed at consumers on how these dates are set, while the latter point could stem from insufficient guidance on the EU level on how to set and communicate on these dates. Last but not least, Member States would continue having different national rules and practices regarding marking and redistribution of foods past the "best before" date, hampering food donation and redistribution.

\section{- Food waste valorisation solutions}

Under this scenario, actors across the food chain would continue to valorise food waste without having complete information about the cost-effectiveness of the chosen valorisation root route. The "food use hierarchy" would not be applied by all actors or Member States and surplus food would be prominently diverted to landfill, creating more food waste.

Furthermore, the Animal by Product legislation would still be poorly interpreted and a greater quantity of food and drink would be disposed as waste rather than being used as an ingredient for animal feed. Alternative crops for feeding animals would continue having an environmental impact on land, carbon and water.

\begin{tabular}{|l|l|}
\hline $\begin{array}{l}\text { Pros additional costs will be necessary at EU or } \\
\text { Member State level, as result to minimal actions. }\end{array}$ & $\begin{array}{l}\text { Cons } \\
\text { Food waste data gaps would persist and grow } \\
\text { between the different sectors within the food supply } \\
\text { chain as well as in between Member States; } \\
\text { Tracking and comparing Member States' progress } \\
\text { towards meeting SDG 12.3 would be impaired; } \\
\text { Consumers would continue wasting edible food } \\
\text { because of unclear date marking; }\end{array}$ \\
$\begin{array}{l}\text { Producers would continue setting "best before" and } \\
\text { "use by" dates on products well before they are no } \\
\text { longer edible (in order to further minimise any health } \\
\text { and safety issues); }\end{array}$ \\
$\begin{array}{l}\text { The "food use hierarchy" 30 would remain an } \\
\text { abstract idea, un-adopted into EU legislation and the } \\
\text { ban on recovering food surplus via animal feed } \\
\text { would remain. Food surplus would therefore not be } \\
\text { redistributed according to the "food use hierarchy", } \\
\text { facilitating food waste disposal at landfills. } \\
\text { Missed opportunity to use food wasted for other } \\
\text { purposes and therefore decrease environmental } \\
\text { impact, increase social and nutritional impact, to save } \\
\text { costs for society. }\end{array}$
\end{tabular}

II. Scenario: Increased food waste quantification in EU-28

This scenario presents a situation in which Member States and actors across the food chain increase their efforts in quantifying food waste by applying existing and foreseen targets, initiatives, and tools. 


\section{Narrative}

Under this scenario, businesses, Member States and food chain actors would start quantifying food waste using the World Resources Institute "Food Waste and Loss Protocol" and the FUSIONS "Quantification Manual". Encouraging such uptake of existent quantification tools would drive the private sector and Member States to gather, monitor, and report food waste data at the different levels of the supply chain and thus leading to a better understanding of the magnitude of food waste and the sectors from which it arises. Furthermore, Member States' obligation to report national food waste levels on an annual basis to the European Commission as demanded by the Circular Economy Package, would be facilitated via the harmonised application of the FUSIONS Quantification Manual. Regular flows of comparable data would enable the European Commission and Member States alike to have a clearer overview of food waste levels across Europe and the key sectors to target in terms of food waste prevention and reduction. Having this information at hand would creating a favourable climate to make educated projections and communicate food waste trends to all actors across the food supply chain

A more optimal food and drink supply chain could be furthermore supported by the results of the pilot testing that is planned to be carried out within REFRESH. Quantitative data will be collected in four pilot countries (Germany, Spain, the Netherlands, and Hungary) in the form of a large scale panEuropean survey. Data collection will take place for the 2.5 year duration of the pilot testing and are expected to bring about useful data per region, as well as per different value chains (pork, fish, beef, bread, food production, processing, retailers, hospitality, consumers, etc.). Each platform would establish a working platform of key stakeholders and influencers in the food supply chain, governments departments and relevant trade bodies. The exchange would also be supported via the development of a European Centre of Excellence IT-based platform (within the REFRESH project).This platform would stimulate food chain actors via its webinars, forums, and information exchange tools.

\section{Pros \\ Stronger EU and MS agenda towards food waste reduction as quantification and reporting will allow better defining, prioritizing and targeting of prevention efforts, as well as tracking progress over time.}

Financial gains for actors across the food chain in the long term as they will be able to track food loss and waste and target hotspots for improvement;

Boost employment potential for the creation of guides and consulting on how to apply food waste quantification manuals, creation of IT tools to facilitate tracking, etc.

Increased awareness on food waste quantities to all actors across the supply chain, in particular towards consumers

\section{Cons}

Costs are foreseen at the Member State level and business level to quantify food waste

Lack of resources and support to carry out quantification throughout all Member States.

III. Scenario: Clarification and simplification of date marking

This scenario assumes that implemented actions optimise understanding and use of date marking by all relevant actors, including food producers, food processors, consumers and national regulatory authorities.

\section{Narrative}

EU and national-wide awareness raising campaigns (based on science-based research) would help educate consumers on how to interpret "best before" or "use by" labels. As the household sector is responsible for more than two thirds of the estimated total of EU food waste and one of its main drivers is linked to date labelling on food products, awareness raising campaigns would have an important impact in terms of food waste prevention and reduction.

Furthermore, via REFRESH work, pan-European evidence-based research on consumer behaviour will be carried out in order to investigate how food supply chain actors could tailor date-marking policies and business strategies in order to drive a more resource efficient food supply chain. ICT tools (sensors, smart fridges, dynamic expiration labels, apps, online diaries, online recipes for cooking with leftovers, etc.) could be used at various stages of the consumption life cycle to support this research. 
Furthermore, on-pack guidance will be developed in order to communicate on whether, when, and how to prepare and store products, in hopes of reducing food waste via awareness raising.

Clear guidelines indicating a set methodology and criteria on how processors/manufacturers should calculate and set "best before" and "use by" dates would be developed. This would eliminate the current practice where processors/manufacturers set these dates well before the date that a product is considered no longer unsafe for consumption. Research will be done on the expansion of the current list of food products exempted from "best before" dates in food labelling (as specified in Annex X of Regulation No.1169/2011). For example, possible food items that could be exempted from food labelling could be flour or rice. The REFRESH pilots will contribute to identifying further hurdles in to date marking along to food supply chain and would provide policy recommendations in this area.

\section{Pros \\ Better date-marking policies and business strategies will drive a more resource efficient food supply chain. \\ Both consumers and business operators will waste less food thanks to clarified confusion around date- marking.}

Financial gains for private sector as product life time will be extended.

Potential for jobs to spread awareness about date marking, the private sector in particular.

Household budget on food could potentially reduce as product life-time "increases".

\section{Cons}

Adjusting date-marking may create uncertainty amongst consumers on the impact on food health and safety;

Increased communication and awareness raising towards consumers about date-marking may generate additional costs for manufacturers and retailers.

\section{Scenario: Guidance on valorisation solutions}

This scenario assumes that more science-based research will support food chain actors to recover food waste at the highest possible level.

\section{Narrative}

A resource efficient food and drink supply chain also requires efforts to reuse food surplus and waste at the highest possible value. The scientific-based research via Life Cycle Analysis and Life Cycle Costs taking place within REFRESH will illustrate the environmental and cost-dimension of valorisation routes and waste management options. This cost analysis would be translated into a state of the art tool to be used by stakeholders and policy makers to evaluate the most beneficial options for waste valorisation and waste management. In this way, the impact can be addressed in relation to the whole life cycle, and the waste management costs for different valorisation options can be compared for the most important waste streams.

REFRESH researchers would also develop new routes for waste valorisation, contribute to the sharing of best practice through networks activities and develop support systems allowing stakeholders to evaluate different options for waste valorisation and waste managements. The research would enhance and underpin the development of innovative applications of food waste in order to increase conversion of unavoidable waste to higher value products, particularly animal feed, food ingredients and chemicals. This will be achieved by tackling critical hurdles to valorisation solutions, notably those related to legislation, business commitment and consumer awareness. Based on the results of the research, the European Commission would clarify the Animal By-Product Regulation (EC) N 1774/2002. The valorisation of waste to feed for non-ruminants and to chemicals, would reduce the GHG associated with the production of animal protein, and reduce GHG associated with petroleum-derived chemical use respectively.

Furthermore, the causes of increased demand of biofuels and the effects on food demand, security, and inadvertent food waste could be enhanced by the continued EU research on biofuels ${ }^{31}$.

\footnotetext{
${ }^{31}$ http://biofuelstp.eu/sustainability.html
} 


\section{Pros}

Development of new routes for valorisation. Reduction of environmental impacts: $\mathrm{CO} 2$ emission when food remains in food chain instead of going to incineration, reducing disposal.

New business opportunities from selling food via alternative channels and job creation opportunities.

Lower waste management costs as less food goes to waste.

Potential for jobs in the food redistribution sector.

\section{Cons}

Evidence-based research may provide conclusions unfavourable to following the food use hierarchy (potentially considering economic costs over environmental costs).

Logistical issues with food redistribution could place a burden on actors within the supply chain.

Table 5.1 Summary: Multi-target approach towards reducing food waste in EU-28

\begin{tabular}{|l|l|}
\hline Business as usual & $\begin{array}{l}\text { No significant changes in the food waste policy with respect to the present day } \\
\text { situation. The BaU scenario reflects a future in which major socio-economic } \\
\text { drivers follow current trends and assumes that there are no major policy changes. }\end{array}$ \\
\hline $\begin{array}{l}\text { Increased food waste } \\
\text { quantification in EU-28 }\end{array}$ & $\begin{array}{l}\text { Member States and actors across the food chain increase their efforts in } \\
\text { quantifying food waste at the most optimized level. }\end{array}$ \\
\hline $\begin{array}{l}\text { Clarification and } \\
\text { simplification of "date } \\
\text { marking" }\end{array}$ & $\begin{array}{l}\text { A better understanding of date marking on the consumer level would be enhanced } \\
\text { by joint efforts from relevant actors, including food producers, and national } \\
\text { regulatory authorities. }\end{array}$ \\
\hline $\begin{array}{l}\text { Guidance on } \\
\text { valorisation solutions }\end{array}$ & $\begin{array}{l}\text { More science-based research will support food chain actors to recover food waste } \\
\text { at the highest possible level. }\end{array}$ \\
\hline
\end{tabular}




\section{Evaluation of scenarios using Impact Assessment Matrices}

During the interviews, experts explored the three scenarios designed in the Setting $A$ and the four scenarios designed in Setting B. The interviews and consultations have:

- assessed implications of these scenarios on food waste reduction nutrition security, environmental quality and socio-economic well-being;

- explored what would be specific research needs specific to each scenario.

The results of each setting are discussed separately in the following two sections.

\subsection{Social innovation and food redistribution activities}

Expert interviews were carried out (see the list of in Annex 1) in July 2016 via telephone and/or Skype. The Impact Assessment Matrix was sent to all interviewees before the interview with a detailed explanation of each scenario.

Prior to the interviews, the scenarios were discussed during the FUSIONS EPM in Brussels (May 20, 2016), where they have been explained and assessed using a focus group method in the framework of a consultation session. A group of experts consisting jointly filled out the Impact assessment Matrix for three Scenarios.

The results of the individual interviews and EPM consultation session can be found in Table 6.1 and in Figures 6.1 and 6.2. It has to be noted that the scores provided are subjective perceptions of the interviewees based on qualitative judgments and are providing a possible direction of expected impacts.

Table 6.1 Impact assessment Setting A $^{32}$

\begin{tabular}{|c|c|c|c|}
\hline & Scenario BAU & $\begin{array}{c}\text { Scenario } \\
\text { Supportive } \\
\text { Legislation } \\
\end{array}$ & $\begin{array}{c}\text { Scenario } \\
\text { Supportive } \\
\text { infrastructure }\end{array}$ \\
\hline \multicolumn{4}{|l|}{ Impact on Food Waste } \\
\hline Potential food waste reduction & $-2 \rightarrow+1$ & $+1 \rightarrow+3$ & $+1 \rightarrow+3$ \\
\hline \multicolumn{4}{|l|}{ Economic impact } \\
\hline pplementation Costs for EU Commission & 0 & $-1 \rightarrow+3$ & $+1 \rightarrow-3$ \\
\hline Implementation Costs for MS & 0 & $-1 \rightarrow+1$ & $-1 \rightarrow+2$ \\
\hline $\begin{array}{l}\text { Implementation Costs for } \\
\text { supply chain stakeholders in MS }\end{array}$ & $0 \rightarrow+1$ & $-1 \rightarrow-2$ & $-1 \rightarrow+2$ \\
\hline Impact on household income & $0 \rightarrow+1$ & $-1 \rightarrow+2$ & $0 \rightarrow+3$ \\
\hline \multicolumn{4}{|l|}{ Social impact } \\
\hline Impact on household behaviour & $-2 \rightarrow+1$ & $0 \rightarrow+3$ & $0 \rightarrow+3$ \\
\hline Impact on product quality & $0+1$ & $0 \rightarrow+3$ & $0 \rightarrow+3$ \\
\hline Impact on food safety & $-1 \rightarrow+1$ & $0 \rightarrow+3$ & $0 \rightarrow+3$ \\
\hline Impact on charities' food provisions & $-2 \rightarrow+1$ & $-1 \rightarrow+3$ & $+2 \rightarrow+3$ \\
\hline $\begin{array}{l}\text { Impact on community engagement in local } \\
\text { kitchens and local food production }\end{array}$ & $0 \rightarrow+1$ & $+1 \rightarrow+3$ & $+1 \rightarrow+3$ \\
\hline \multicolumn{4}{|l|}{ Environmental impact } \\
\hline Impact on efficient natural resource use & $-2 \rightarrow+1$ & $+1 \rightarrow+3$ & $-1 \rightarrow+3$ \\
\hline Impact on GHG emission & $-2 \rightarrow+1$ & $+1 \rightarrow+3$ & $-1 \rightarrow+3$ \\
\hline
\end{tabular}

32 In Table 6.1 the range ( $\min$ and $\max$ ) of the perceived scores is presented. 


\begin{tabular}{|l|c|c|c|}
\hline Nutritional impact & & +1 & $+2 \rightarrow+3$ \\
\hline $\begin{array}{l}\text { Impact on needy people in terms of their } \\
\text { nutrition }\end{array}$ & & & $+1 \rightarrow+3$ \\
\hline Other issues & $\mathrm{NA} \rightarrow+3$ & $-2 \rightarrow+3$ & $+2 \rightarrow+3$ \\
\hline Feasibility of the scenario & $\mathrm{NA} \rightarrow+2$ & $+1 \rightarrow+3$ & $+1 \rightarrow+3$ \\
\hline Practicality to implement the scenario & & \\
\hline
\end{tabular}

Table 6.2 Scoring system for the impact assessment of scenarios

\begin{tabular}{|c|c|}
\hline+3 & Major positive change \\
\hline+2 & Significant positive change \\
\hline+1 & Positive change \\
\hline 0 & No change \\
\hline-1 & Negative change \\
\hline-2 & Significant negative change \\
\hline-3 & Major negative change \\
\hline NA/NR & Not Available/Not Relevant \\
\hline
\end{tabular}

\section{Scenario: Business as usual (BaU)}

\section{Impact on food waste reduction}

By summarising the results of all interviews on the impact assessment of three different scenarios it can be concluded that Business as Usual will have a slight moderate impact on food waste reduction as a result of currently ongoing activities such as 1 ) created awareness in the society 2) national objectives to reduce food waste in certain MS 3) on-going awareness campaigns, initiatives in the sector and social organizations.

Some of the interviewees have indicated that BAU can be classified as the worst-case scenario and it will be a shame if this scenario takes off. Currently there are lots of potentials and opportunities in food donation/redistribution activities across different $M S$ and they need to be supported by governments through legislations.

If the BAU will take off with no common dedicated framework at EU level, MS may take individual actions thus leading to more diversity among MS. This suggests a very fragmented landscape across $\mathrm{MS}$ in the EU, since this suggest that some MS will take initiatives to tackle the problem, while others will not. It will depend entirely on the agenda of individual MS and relevance attached by each MS to the problem.

\section{Economic impact}

The EU will not counter direct costs from BAU since no adjustment and/or implementation costs for new legislations are required. However indirect costs could be higher, where food which is not donated/redistributed will be wasted, thus increasing environmental social and nutritional impact and increasing costs for society. Thus the cost of not implementing can be very high too.

\section{Social Impact}

The social impact in general is expected to be between zero and moderately positive as a consequences of already existing food waste reduction initiatives.

\section{Environmental impact}

The environmental impact is perceived to be between negative and moderately positive due to different interviewees averaging into no impact.

\section{Nutritional impact}

Nutritional impact is assumed to be slightly positive as a result of currently ongoing activities, however not very high.

\section{Feasibility}

The feasibility of this scenario has been judged as being moderately feasible, where some interviews have positive expectations that this scenario will not take off, while others consider that this scenario is likely feasible. 


\section{Scenario: Supportive legislations}

\section{Impact on food waste reduction}

The results for this scenario in general are rather controversial. The expected impact on food reduction ranges between moderate positive to significant positive.

\section{Economic impact}

Regarding the costs, it is assumed that this scenario will not be very costly for the EU, since changing/rewriting pure legislations do not require significant investments. However MS might incur higher costs to implement legislations and this will result in major differences between states. The chain stakeholders may incur in significant costs since stricter regulations related to e.g. PAYT schemes imply costs if food is wasted. Besides, the creation of immature infrastructure of redistribution by business will imply addition costs (e.g. the development of new business models to redistribute or process surplus). However these costs might be outweighed by the creation of tax incentives (e.g. tax credits on donated food and adjustment of VAT) and by creation of additional value from food otherwise to be wasted. Suggestion has been made that conversion of already existing funds such as conversion of FEAD funds would create a positive effect without additional budget.

\section{Social Impact}

The perceptions regarding food quality and safety are rather positive within this scenario and it is assumed to have a significant positive impact on these two aspects. This is due to the fact that better clarified and harmonised regulations translate into better food safety and thus food quality.

\section{Environmental impact}

The expectations regarding the environmental impact are ranging between significant and major positive. This is related directly to food waste reduction possibilities through legislations and its direct impact on environment.

\section{Nutritional impact}

Nutritional impact on needy people is perceived to be between significant and major positive, assuming that the food otherwise wasted will be donated to people in need if the supply chain members have to comply with the regulations.

\section{Feasibility}

The feasibility of this scenario was in general perceived to be very difficult to be judged by experts. This is due to fact that there is a little evidence available on its real impacts (e.g. the lack of hard data and estimations on food waste amounts not donated/redistributed and the costs related to that). The major drawbacks related to feasibility and practicality of this scenario are perceived to be the following:

- Very strong incentives for donation may cause actors to decrease other food waste prevention efforts (efforts to decrease food waste generation in the first place). Besides, strong regulations to decrease food waste in the chain via regulations, may rise other problems such as that edible food may be used not for donation purposes, but for feed or composting purposes. Hereby is important that food hierarchy should be respected and monitored by policy.

- The entire package of legislation would be very difficult to pass. It takes a long time to change policies at EU-level and consequently at MS-level.

- It might have limited implementation without supportive infrastructure related to realisation of the surplus, logistics and capacity for redistribution.

- It was noted the application of the Good Samaritan Law on a EU level is quite controversial and also complicated and may not work very well. Voluntary agreements between the manufactures and food banks could be much more effective.

An important remark for the Supportive legislation scenario is that the supportive legislations will require alignments of several policy domains and cooperation's with other policies such as policies related to environment, economy, poverty, health benefits.

The quality of these legislative measures is very important (e.g. an example of edible food going to compost or biofuels due to favourable policies in these domains or example of FEAD that spends money in buying new products instead of using leftovers-see chapter 4.1.). It is important to have a dialogue with all parties involved when adjusting legislations to avoid irreversible effects and perverse 
subsidies, and the legislation should not favour one stakeholder specifically. It should define equal rules for all organizations involved dealing with food waste.

III. Scenario: Supportive infrastructure

Impact on food waste reduction

This scenario is expected to have significant positive impact on food waste reduction.

\section{Economic impact}

Regarding the economic costs, according to the experts this scenario will induce major costs for the EU and MS. An estimate has been suggested that the ratio of these costs will be $15 \%$ for EU and $85 \%$ for MS. The chain stakeholders involved in donation/redistribution activities on their turn will have financial gains.

\section{Social impact}

The social impact will also be positive, since this scenario will stimulate new business opportunities from selling food via alternative channels and job creation opportunities. Besides the redistribution of surpluses will help charities to provide healthier and more varied diets for vulnerable people within communities.

\section{Environmental impact}

The environmental impact has received more controversial assessment. On one hand food waste reduction will have positive impact on the environment, however an intensive redistribution and logistics might increase $\mathrm{CO} 2$ emissions.

\section{Nutritional impact}

Although nutritional impact on needy people is perceived to be between positive and major positive, some respondents voiced the possibility that the new infrastructures may divert food intended for donation to other purposes.

\section{Feasibility}

Similarly to the scenario above the feasibility and practicality of implementation of this scenario is hard to assess for interviewees. This scenario requires major investments from EU and MS, and only if these investments will be in place the feasibility might be higher than the scenario " supportive legislations". The major drawback of this scenario is that by only supporting the infrastructure, food donation activities might slightly increase, however there are still disincentives related to legislations hampering food donations that need to be addressed to have real effect.

An important remark concerning this scenario is that it should enable entrepreneurs to create financial added value. This means that the financial subsidies and funds should be designed in a such way to enable starting entrepreneurs to create sustainable business models. However this is connected to legislation (e.g. competiveness, the fear of retailers to create a parallel market to consider and solve preconditions around entrepreneurship/incentives). A few experts indicated that they believe that there is a large opportunity for social-economic organizations to stimulate social employments (e.g. social economy), potential for jobs, food valorisations into new products. Lots of products are currently distributed in packages, but there are alternative ways to make these products last longer e.g. turning them into soups). The market price for a such soup should not necessarily be high or low compared to the price of standard soup. But for other products - more expensive to be produced due to logistics, infrastructure, etc - subsidies will require to be able to market them. Besides, this may have a negative impact on irregular consumers (i.e. people in need) who might otherwise receive these food via foodbanks.

It was mentioned the importance of introduction of soft measures such as dialogue by creating guidelines for donation, supporting online platforms, communication via online (e.g. Belgian platform www. schenkingsbeur.nl). Note that similar recommendation to open up a dialogue encouraging dialogue around food reduction and redistribution has been suggested in the Fusions Policy Brief (May 2016). It has been suggested that there is a need to open dialogue on the EU level concerning lessons learned along with potential areas of development. Actors across the food chain such as project managers, individuals in the academic sector, as well as commercial organisations could be brought together to launch dialogue on relevant EU-wide issues related to food waste prevention and food surplus management using e.g. annual physical or virtual conference on European food reduction and redistribution. 


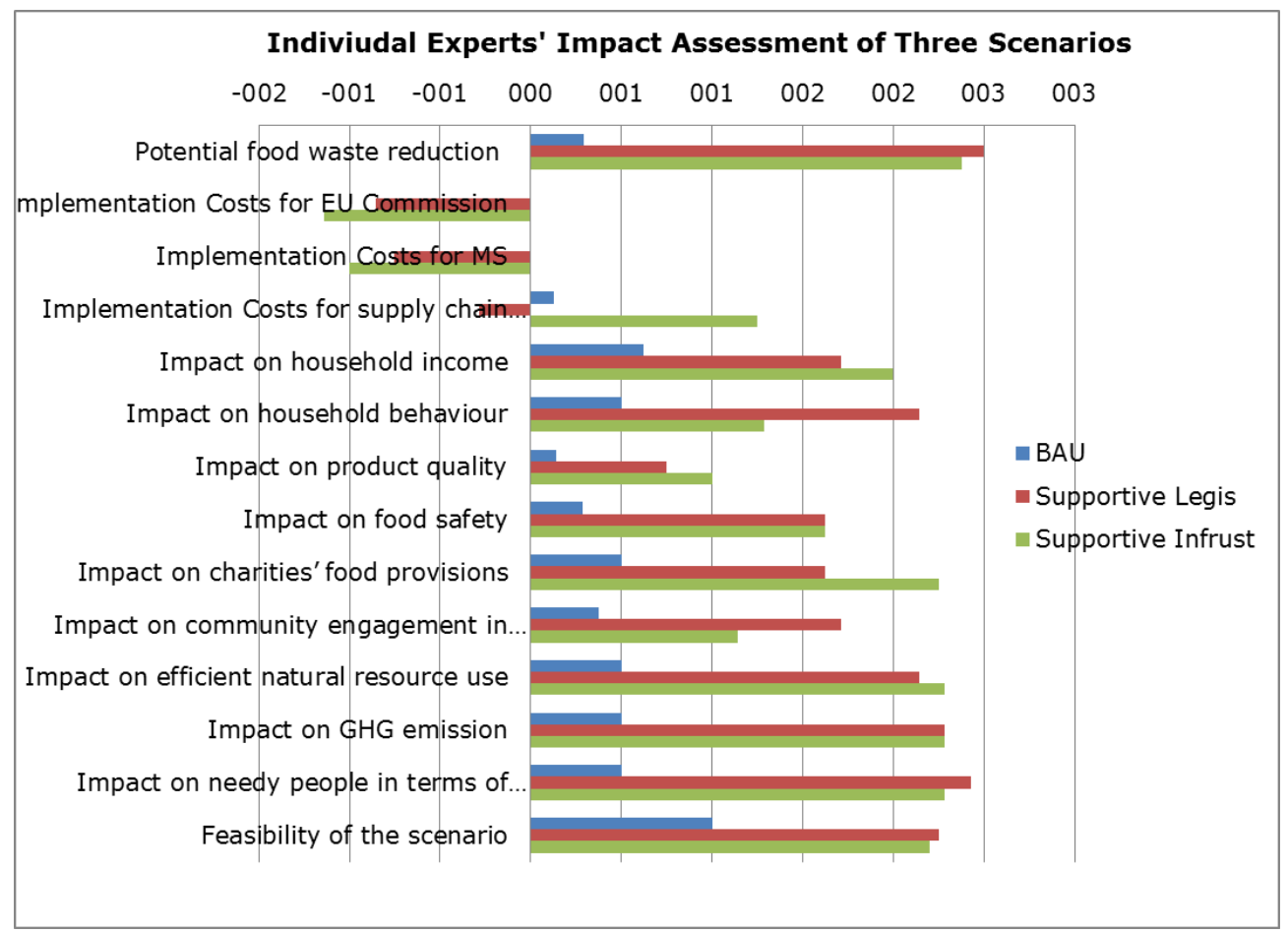

Figure 6.1 Individual Experts' Impact Assessment of three scenarios

Summarising the joint results from individual interviews and the FUSIONS EPM consultations session of two scenarios (see graph below) it can be concluded that Scenario "supportive infrastructure" scores slightly better for several items compared to "supportive legislation". However the differences are rather nihil. It was concluded that BAU offers a small positive improvement in comparison to the actual situation. However it was suggested that the mix of these two scenarios offers real potential for food waste reduction through donation/redistribution. The biggest positive change should take place in scenario " supportive infrastructure" as an evolution of scenario "supportive legislation". There is a need for a balance between infrastructure and legislation to achieve good results. Next to this in order to be able to judge the feasibility of the scenarios there is a need to test scenarios using hard data. It will be necessary to prove that environmental and social costs related to food waste and to poverty will decrease when these two scenarios are combined as it will require substantial investments and finances for the working costs once installed. Experts suggest that the practicality to implement scenario "supportive legislation" could be higher because there is currently a political momentum for food donation/redistribution. Scenario " supportive infrastructure" could be more difficult due to the economic crisis. Moreover, it has been suggested that although increasing food donation and redistribution activities will improve food waste reduction considerably, it will still address food waste reduction only partly. Food donation/redistribution should be addressed in combination with other food waste reduction measures. 


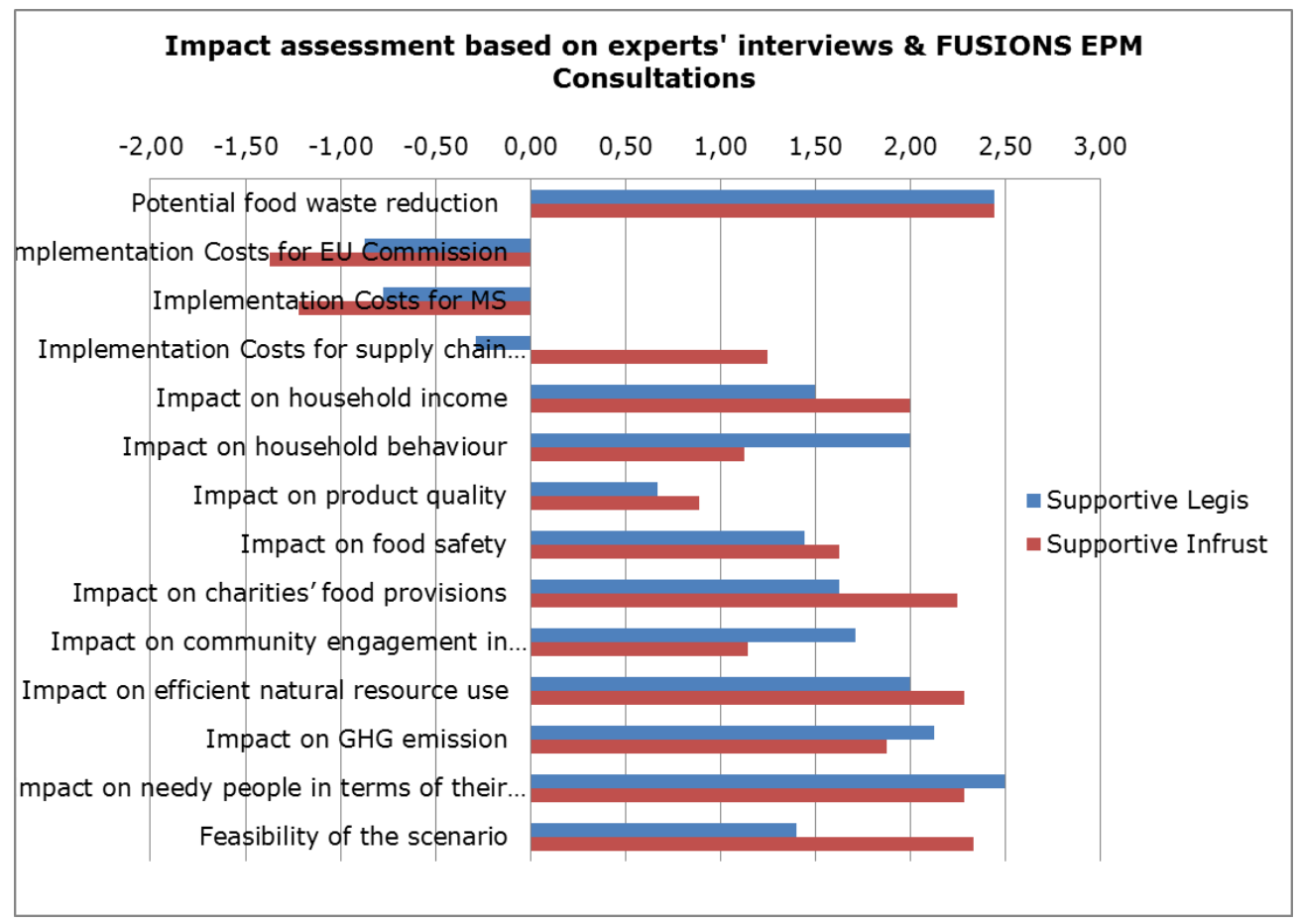

Figure 6.2 Impact assessment based on experts' interviews \& FUSIONS EPM Consultations 


\subsection{A multi-target approach towards reducing food waste in EU-28}

Expert interviews were carried out (see Annex 1 for the list of interviews) in July 2016. The interviews were carried via telephone or email exchanges. The Impact Assessment Matrix was sent in advance to all interviewees with a detailed explanation of each scenario. Below are the findings of these experts along with descriptive explanations of the different scores per scenario.

Table 6.3 Impact assessment Setting B

\begin{tabular}{|c|c|c|c|c|}
\hline Impacts & $\begin{array}{l}\text { Business } \\
\text { as Usual }\end{array}$ & $\begin{array}{c}\text { Increased } \\
\text { food waste } \\
\text { quantification } \\
\text { in EU-28 }\end{array}$ & $\begin{array}{c}\text { Clarification } \\
\text { and } \\
\text { simplification } \\
\text { of date } \\
\text { marking } \\
\end{array}$ & $\begin{array}{c}\text { Guidance } \\
\text { on } \\
\text { valorisation } \\
\text { solutions }\end{array}$ \\
\hline \multicolumn{5}{|l|}{ Quantitative impact on food waste reduction ( $t$ ) } \\
\hline Primary production & $0 \rightarrow+1$ & 0 & 0 & +2 \\
\hline Manufacture/Processing & $0 \rightarrow+1$ & +2 & +2 & +2 \\
\hline Retail/wholesale & $0 \rightarrow+1$ & +3 & +2 & +1 \\
\hline Household & -2 & +1 & +3 & 0 \\
\hline \multicolumn{5}{|l|}{ Economic impact } \\
\hline $\begin{array}{l}\text { Implementation costs for food waste reduction } \\
\text { actions at European Commission level }\end{array}$ & -1 & -1 & -1 & $0 \rightarrow-1$ \\
\hline Implementation costs for MS & -1 & -2 & -1 & 0 \\
\hline Costs for food loss in primary production & 0 & -3 & 0 & 0 \\
\hline Costs for food waste in Manufacture/Processing & 0 & -2 & $-2 \rightarrow+2$ & +1 \\
\hline Costs for food waste in Retail/wholesale & 0 & -1 & -1 & +1 \\
\hline Implementation costs for Household & 0 & $-1 \rightarrow 0$ & 0 & NR \\
\hline \multicolumn{5}{|l|}{ Social impact } \\
\hline $\begin{array}{l}\text { Impact on awareness level of food waste/loss } \\
\text { and its consequences amongst consumers }\end{array}$ & -2 & +1 & +1 & NR \\
\hline Impact on product quality and food safety & 0 & 0 & -1 & 0 \\
\hline Impact on employment & +1 & +1 & +1 & +1 \\
\hline \multicolumn{5}{|l|}{ Environmental impact } \\
\hline Impact on efficient natural resource use & -1 & +1 & +1 & +2 \\
\hline Impact on GHG emission & -1 & +1 & +1 & +2 \\
\hline \multicolumn{5}{|l|}{ Other issues } \\
\hline Feasibility of the scenario & 0 & +1 & +2 & +1 \\
\hline Practicality to implement the scenario & NA & -1 & +1 & +1 \\
\hline
\end{tabular}

\section{Scenario: Business as usual}

\section{Impact on food waste reduction}

The results of the interviews suggest that the BaU scenario will initially have very little or close to zero positive impact on food waste reduction in the primary production, processing and retail sector. However experts consider that although quantification across the food supply chain sector is not yet harmonised, date marking is not being simplified etc. existing trends in the BaU scenario are to improve efficiency and reduce food waste. Thanks to the Circular Economy package and the SDGs, actors across the food chain now have a food waste reduction target and a Protocol to start quantifying food waste. Furthermore, awareness raising has increased during the past four years thanks to research projects such as FUSIONS and social innovative projects. REFRESH, a H2020 European project, was launched last year illustrating the need to provide evidence based-research to food chain actors and accompany these in the reduction of food waste. On the other hand, experts believe that household food waste levels tend to increase without policy interventions and awareness raising. The $\mathrm{BaU}$ scenario will therefore have a negative impact on food waste reduction in households. 


\section{Economic impact}

According to the interviewed experts, the BaU scenario will require implementation costs for food waste reduction and the EC level given the revision of the Circular Economy Package and the launch of the H2020 project REFRESH. Significant resources would be required from the EC in terms of communication/awareness raising, call for tenders-to pay for contractors, etc. Member States however will not increase their costs as there is yet no new legislation to be transposed from the Circular Economy package and quantification has not yet started at the national level. However some Member States might launch national studies on food waste quantification voluntarily (such as France). The economic impact of the BaU scenario on the primary sector is very difficult to identify mainly because of definitional issues and lack of data. It is however expected from them not to carry any costs within this scenario. Very little impact is expected at the processing and retail level in the absence of food waste quantification, date marking simplification and valorisation solutions. As for the household sector, they would benefit from savings if less food waste occurs.

\section{Social impact}

The BaU scenario will have a negative impact on awareness raising of food waste and loss amongst consumers mainly because of lack of food data baseline and lack of clarification of dates. No significant changes will be made to product quality through the BaU scenario, as product quality standards in Europe are currently very strict. This scenario would ensure that product quality would be maintained as a high priority. The (small) positive impact on employment within this scenario is due to socially innovative projects that are in force to address food waste (such as the Food Surplus Entrepreneurs network).

\section{Environmental impact}

Experts believe that the BaU scenario will have a negative environmental impact both on the efficient natural resource use and on GHG emissions. Although FUSIONS research illustrates the magnitude of food waste in EU-28 via quantitative, economic and environmental estimates, there is still no strong evidence to suggest that current EU-28 food waste has declined since initial estimates derived from 2006 data. There are still important differences in data methodology and scope in the different Member States.

\section{Feasibility}

The feasibility of this scenario has been judged as being moderately feasible, where some experts consider that this scenario is likely feasible: food chain actors are already progressing in terms of quantification, date marking, valorisation solutions etc. This will be detailed in the coming scenarios.

\section{Scenario: Increased food waste quantification in EU-28}

\section{Impact on food waste reduction}

In this scenario, food business operators will start using a harmonized methodology to quantify food waste. According to experts, food waste quantification does not change any food waste levels as such but it is a prerequisite for following up of any targets. By measuring, actors across the food chain push food waste drivers up on the agenda. Experts agreed that food waste quantification will only slightly impact food waste reduction at the primary sector level by informing actions which can have a positive impact. Benefits in terms of food waste reduction might be more in relation to valorisation solutions and not to quantification at the level of the primary sector.

The impact of quantifying food waste within the manufacturing sector depends more on the level of commitment within organisations and whether or not it results in understanding the underlying drivers. It is not certain that quantification will be able to show the level of granularity that is needed to have an impact on food businesses such as production units, inputs to production \& QA issues with final product.

Via proper use of a quantification methodology (such as the WRI FWL Protocol), more impact will be done at the retail level as they have greater public facing profile: if quantification results in greater transparency (not guaranteed) this would add pressure to further waste prevention (reduction in damaged product, better demand management systems, increased redistribution back of store).

Quantification of food waste can help raise consumers' awareness at the household sector and can have a small impact on food waste reduction.

\section{Economic impact}


Experts believe that it is difficult to assess the economic impact within this scenario, since it depends on which level of detail the food waste is to be reported and which systems are needed to support the collection for data. If Member States will start quantifying food waste using a common methodology as required in the Circular Economy Package, there will be costs that will most likely fall on the Member States. The costs will be quite high at the primary sector as very few countries have routines and methodologies for measuring food waste as shown by FUSIONS research.

For the manufacturing sector, it is expected that the amount of money spent on applying the quantification manuals would initially cost a lot (as manufacturers/processors will restructure their current reporting methods and may seek external assistance), however the cost will surely go down over time. However, knowing food waste totals does not significantly change current business practices. Embedding measurement within unit production processes and development of 'Lean' within manufacturing would result in better understanding of the full costs of food waste.

At the retail sector, the economic impact will be slightly less, as data are in most cases available but need to be collected and evaluated. Data may be retrieved via the retailers' business system as well as via the municipal waste management system. Furthermore, retailers might need to invest in SKU level data recording of unsold product. Few retailers have adopted such systems currently, but the product level quantification of food waste is an essential part of understanding the underlying causes, identification of hotspots etc.

An increase in quantification at the household sector will have an important economic impact as waste streams are more mixed and harder to categorize. The quantification will only slightly impact consumers themselves. They could benefit financially from savings if less food waste occurs, but this is not the same as an 'implementation cost'.

\section{Social impact}

The large positive impact on employment within this scenario is due to employment opportunities for consultancies, research organisations, and social entrepreneurs to provide additional solutions to complement and reinforce existent actions. A consequence of quantification initiatives the stakeholder will be more aware, it could either lead to that the stakeholder implements changes leading to that less food will be available for donations as the food is sold instead or that the stakeholder realises that one way of decreasing food waste is food donations and thus the amount of food available for food donations will increase. Considering the small amount of food donated in 2016 relevant investments in awareness raising should lead to a significant increase of donations.

\section{Environmental impact}

A moderate-to-large positive change on the impact on GHG emissions is expected within this scenario via optimised quantification practices with the application of harmonised quantification methodologies.

\section{Feasibility}

Experts considered that the feasibility of this scenario is moderate, where some considered it difficult to assess. Although food chain actors are currently testing the WRI Protocol, it is less likely that Member states start quantifying food waste in the short term. It is expected to invest a reasonable amount of money before quantifying food waste across the food supply chain and at the national level.

\section{Scenario: Clarification and simplification of date marking \\ Impact on food waste reduction}

This scenario assumes that date marking will be clarified and simplified across the food supply chain. Experts believe that date marking has little to do with primary production as most products are delivered from primary production to processing in bulk amounts without any date, hence the zero change in impact.

On the other hand, date marking clarification could result in some benefits, especially at the manufacturing and processing sector. According to one of the interviewed experts, date marking has less to do with 'use by' versus 'best before' confusion and more to do with product like extension and the operation of 'minimum life on receipt criteria' imposed by retailers on their suppliers, the 'buffer' time that is assumed between total product life and the date life used on the product: for many products this buffer exceeds food safety requirements by a significant margin and could be safely reduced on some product types. This issue is part of the 'clarification' issue on date markings and has significant implications on supply chain food waste and consumer food waste for more perishable products. 
Within this scenario, date marking will have a bigger impact in terms of food waste reduction at the wholesale/retail sector as products will be in stock for longer (with a longer expiration date), leading to a longer lifetime before reaching the consumer. Experts argue that any changes to date marks will need to involve retailers and their suppliers. If date marks are set inappropriately and product quality is too poor at 'best before' expiry, then retailers will have more food waste in store.

The household sector would be able to keep products for a longer period of time, leading to a significant change in food waste reduction. Experts believe that better date marking is also expected to have a positive impact in household waste reduction but only if adapted to consumer perception and combined with consumers training on the new date labels.

\section{Economic impact}

This scenario will generate economic costs for the EU and MS if new research is mandated within this area and if the enforcement of a new legislation is required at the national level. Interviewed experts believe that the Commission will probably need to consult widely across all Member States competent authorities, food businesses and trade bodies. This could require significant resource commitment from the Commission in order to research a EU level solution.

With regards to the manufacturing sector, the economic impact starts very negative and ends up as a positive change. The amount of money spent on applying new norms on date marking will initially cost a lot (as manufacturers/processors will restructure their current guidelines on applying dates, and may seek external assistance), however the cost will surely go down over time. For the wholesale/retail sector, communication/awareness raising will incur high investment, as communication material will have to be implemented in stores to ensure consumer understanding of any changes in date markings. This type of communication may be outsourced to external contractors. In both cases, there will be a negative change in terms of economic impact.

For the household sector, communication on the EU, MS, and private level on quantification and date marking may enhance consumer understanding of food waste and in turn, lower their costs related to disposing of food when it is still edible which would lead to over-purchasing.

\section{Social impact}

Experts believe that under this scenario, there would be a small negative impact on product quality and food safety as there is still a risk towards compromising food safety via oversimplification of date marking, especially for perishable product categories. If reform of date marks includes consideration of product life extension then it could impact on product quality/ food safety if date marks are set too close to 'peak product quality'. The positive impact on employment within this scenario is due to employment opportunities for consultancies, research organisations, and social entrepreneurs to provide additional solutions to complement and reinforce existent actions.

\section{Environmental impact}

A moderate-to-large positive change on the impact on GHG emissions is expected within this scenario via optimised date marking practices with the application of expected guidance on the topic. However, one expert believes that date marking should be combined with a decreased food production, otherwise there would be much more products on the market at the same time (as the products last longer). The risk is that the same amounts are produced and in addition the shelf life increases - this leads to more products on the market.

\section{Feasibility}

Interviewed experts considered that this scenario is the most feasible one as actions are already under way. The European Commission (DG SANTE) has already launched a call for tender to study the simplification of date marking at the EU level and its implication on food waste. This future study will also analyse the possibility to extend food durability for a certain type of food products. Furthermore the pilots launched in the framework of the REFRESH project will also support the clarification of date marking and its link to food waste.

\section{Scenario: Guidance on valorisation solutions \\ Impact on food waste reduction}

Interviewed experts unanimously agreed that food waste valorisation opportunities are either not known or not being made available to all food chain actors. Increased guidance on valorisation solutions should therefore have a positive effect on food waste reduction. The primary production sector will highly benefit from new valorisation solutions, particularly in the meat and fresh fruit \& 
vegetables sectors where alternative markets for unsaleable product will have some influence on food waste. Moreover, better logistics and clarification of animal feed guidance will ensure that more edible surplus produce and by-products at farm level is diverted to animal feed.

It is also expected that food waste valorisation opportunities have a further positive effect in the processing sector. Guidance and options would be very useful and could lead to substantial reduction in this sector. It is however expected for this sector to have a higher impact on food waste reduction as more food surplus is produced at this level. Valorisation opportunities are less applicable to retail than primary production or manufacture/processing. However experts believe that valorisation solutions are important at the retail level as they will support better logistics and sales strategies. An overview of the mechanic separation of packaging from the food (waste) may be also useful in this area for valorisation purposes and may help choosing appropriate options.

Two sectors to be highly impacted by further valorisation solution are the catering sector and household. According to interviewed experts, general economic and environmental advantages of recycling catering and household food waste into animal feed, would only be possible if the EU Regulations on ABPs were to be changed (Reg. 1069/2009 and implementing Reg 142/2011).

\section{Economic impact}

Increased valorisation guidance and scientific-based research via Life Cycle Costs taking place within REFRESH will illustrate the cost-dimension of valorisation routes and waste management options. Experts believe that increased valorisation will require significant resources from the EC. In particular, discussion on valorisation via ABP would cost many resources, as this is a highly sensitive topic. In terms of economic costs for MS the impact is quite limited as valorisation solutions are likely to be enacted at a company level rather than at MS level. The primary production sector is expected to benefit from valorisation solutions, although these will need to be cost-neutral for the company i.e. offset against savings in disposal costs. Increased valorisation solutions are expected to have limited economic impact at the retail and household level. However, life cycle cost analysis might shed light on which valorisation solutions are more profitable for the sector, having thus a positive impact on its finance.

\section{Social impact}

In terms of social impacts, it is expected the employment opportunities under this scenario will increase. However, this may be mitigated by some loss of employment in the waste management/anaerobic digestion \& composting sectors.

\section{Environmental impact}

A large positive change on the impact on efficient natural resources is expected within this scenario as energy can be generated via anaerobic digestion and new innovative forms of valorisation may reduce the amount of natural resources currently being used. Furthermore, in the most comprehensive study to date on the issue, researchers at Cambridge University conclude that turning catering waste into pig feed has significantly more environmental benefits than biogas or composting. The major environmental benefit of increased valorisation via animal feed, lies in the reduced land use change due to reduced demand for soya as a key conventional feed ingredient. The impact is more significant for catering waste, given that there is less potential for other types of valorization/redistribution and this can be a source of protein. The life cycle analysis within the REFRESH project will contribute to this research.

A moderate-to-large positive change on the impact on GHG emissions is expected within this scenario via optimised date valorisation practices thanks to a generally better understanding of the food use hierarchy. However, the GHG emissions will depend on the overall input required across all scenarios e.g. extra energy to valorise the food waste. The drivers at company level are likely to be economic not environmental.

\section{Feasibility}

The feasibility of the interviewee was perceived in a rather positive manner. The research undertaken in the framework of REFRESH will help identifying new valorisation solution and will provide food chain actors with the necessary tools to assess the least costly solutions for their waste. Some experts believed that the clarification of the Animal by Product Directive will be very challenging, while others argued that the insights of the REFRESH project will show enough evidence for the revision of this Directive. 


\section{Conclusions and recommendations}

This study was aiming to identify and analyse targeted policy interventions addressing the most relevant food waste drivers by developing several policy scenarios focusing on two selected settings: Food donation and redistribution in a context of social innovation (Setting A), A multi-target approach towards reducing food waste in EU-28 (Setting B). The analysis was based on qualitative comparative method using exert assessment of a number of alternative scenarios focusing on selected policy interventions in order to evaluate food waste reduction possibilities in Europe in light of the 50\% food waste reduction by 2030 at retail and consumer level as foreseen by the SDG (Sustainable Development Goal) goals. A number of experts interviews were carried out to assess 7 scenarios (three in setting $A$ and four in setting $B$ ) in terms of their impact on food waste reduction, economic, social and environmental aspects. Besides the feasibilities and practicalities of the scenarios of the scenarios have been assessed.

In the setting Food donation and redistribution in a context of social innovation the Business as Usual scenario might be seen clearly as a worst case. The current situation might be characterized by limited food waste reduction possibilities related to (i) ongoing awareness campaigns, (ii) initiatives from social organizations and (iii) national objectives to reduce food waste in certain MSs. Such a scenario would lead to a very fragmented landscape across the EU with only some MSs taking targeted initiatives to address the problem. The direct economic costs for the EC might be relatively limited (close to zero) since no adjustment and/or implementation costs for new legislations would be require. However indirect costs might remain high due to the environmental, social and nutritional impacts of food waste.

The scenarios Supportive legislation and Supportive infrastructure are complementary to each other. Both scenarios offer a significant potential, nevertheless the interviews suggest that the mix of the two might lead to unlock the higher potential in terms of food waste reduction. The major positive change should take place in the scenario "supportive infrastructure" as an evolution of the scenario "supportive legislation". There is ample room for a better integration between infrastructure and legislation to achieve positive outcomes. However a major limitation might be represented by the substantial investments required to develop and maintain these infrastructures. A comprehensive assessment of the environmental and social costs related to food waste and poverty could provide important evidences to justify and motivate these investments.

In the setting Multi-target approach towards reducing food waste the Business as Usual scenario will have a negative impact on food waste reduction, although awareness raising has increased during the previous years thanks to different food waste related projects and initiatives. However, in the long run, without additional support from governments to implement targeted policy interventions food waste might tend to increase. The economic, social and environmental impacts are assessed as limited.

The scenario Increased food waste quantification in EU-28 assumes moderate food waste reduction across the entire supply chain with the highest impact expected at retail level and the lowest at the primary production. The economic impact in terms of costs will also vary across the entire supply chain, with the manufacturing sector expected to face the higher initial costs due to the application of the FUSIONS quantification manual methodologies and the retail sector presenting slightly lower costs although data need to be gathered and analyzed in most of the cases are already available. The social impact of this scenario is expected to be positive due to increased employment opportunities for consultancies and research organisations. Environmental impact is expected to range between moderate to largely positive thanks to the optimised quantification practices related to the application of harmonised quantification methodologies.

The scenario Clarification and simplification of date marking is characterized by significant positive change in food waste reduction, with the highest impact expected at wholesale and retail level. The impact on the household level is also expected to be relatively high but only in case of the implementation of consumer focused trainings on date labels. The potential costs for the EU and for MSs are relatively high as a result of a wide consultation across all Member States competent authorities, food businesses and trade bodies regarding the enforcement of the new legislation. Social impact is expected to range between slightly negative (e.g. compromising food safety) and slightly positive for the potential creation of employment opportunities for consultancies, research organisations, and social entrepreneurs that could be asked to provide additional solutions to

FUSIONS - Scenarios on current trends of food waste generation | 57 
complement and reinforce existent actions. The environmental impact is expected to range between moderate to large due to optimised date marking practices with the application of the improved guidance.

The scenario Guidance on valorisation solutions is characterized by a positive impact on food waste reduction across the entire supply chain. The primary production sector will highly benefit from new valorisation solutions and alternative markets for unsaleable products will have a positive influence on food waste reduction (e.g. in the meat and fresh fruit \& vegetables sectors). Similar expectations are foreseen for the processing sector as more food surplus is produced at this level. The overall cost for the EC is expected to be relatively high in particular for certain valorization streams as those based on animal by-products. Social impact will be relatively positive especially due to the creation of new employment opportunities. A large positive change is expected in terms of environmental impact for instance due to the generation of energy via anaerobic digestion and other innovative forms of valorization that may reduce the amount of natural resources currently used.

The scenario analysis lead to the identification of a set of emerging issues to be considered for the development of potential recommendations:

- Very strong incentives for donation may cause actors to decrease other food waste prevention efforts (efforts to decrease food waste generation in the first place). Besides, strong regulations to decrease food waste in the chain via regulations, may rise other problems such as that edible food may be used not for donation purposes, but for feed or composting. Hereby it is important to ensure that policy interventions consider the food hierarchy.

- The revision of policy and legislations supporting food donation and redistribution activities should be based on an extended dialogue among different policy domains: environment, economy, poverty, health etc. A better coordination would reduce the risk of irreversible effects and perverse subsidies. Moreover revised legislations should not favour one stakeholder specifically and should define fair rules for all organizations engaged with food donation and redistribution.

- A mix of "supportive legislation" and "supportive infrastructure" offers high potential for food waste reduction via food donation and redistribution, where the major positive change should take place in "supportive infrastructure" as an evolution of the scenario " supportive legislation". This may require substantial costs and incentives from government. There is ample room for a better integration between infrastructure and legislation to achieve positive outcomes. However a major limitation might be represented by the substantial investments required to develop and maintain these infrastructures. A comprehensive assessment of the environmental and social costs related to food waste and poverty could provide important evidences to justify and motivate these investments.

- Suasive measures matters. A relevant role in food waste reduction can be played by the stimulation of dialogue around food donation and redistribution by creating guidelines for donation, supporting online platforms, open dialogue on the EU level concerning lessons learned along with potential areas of development.

- The introduction of voluntary agreements between manufactures and food banks can provide good potential to increase the effectiveness of food donation and redistribution activities.

- The introduction of a harmonized methodology for the quantification of food waste represent a crucial step to improve the position of food waste in the agenda of policy makers and therefore to stimulate food waste reduction through the initiatives undertaken by food donation and redistribution activities.

- Date marking has less to do with 'use by' versus 'best before' confusion and more to do with product like extension and the operation of 'minimum life on receipt criteria' imposed by retailers on their suppliers, the 'buffer' time that is assumed between total product life and the date life used on the product. For many products this buffer exceeds food safety requirements by a significant margin and could be safely reduced on some product types. This argument is part of the 'clarification' issue on date markings and has significant implications on supply chain food waste and consumer food waste for more perishable products.

- Life cycle cost analysis might shed light on which valorisation solutions are more profitable and for which sector of the food supply chain. 
- Experts suggest that general economic and environmental advantages from recycling catering and household food waste into animal feed, would only be possible if the EU Regulations on ABPs were to be revised (Reg. 1069/2009 and implementing Reg 142/2011). 


\section{References}

Alexander C., Smaje C. (2008) Surplus retail food redistribution: An analysis of a third sector model. Resources, Conservation and Recycling 52 (2008) 1290-1298.

Aunkofer F. (2015) Erhebung von Lebensmittelverlusten im ökologischen Gemüsebau (Assessment of vegetable losses in organic farming). Master thesis at BOKU-University of Natural Resources and Life Sciences, Vienna.

Bill Emerson Good Samaritan Food Donation Act, 1996. Conversion to permanent law of Model Good Samaritan Food Donation Act and Transfer of that Act to Child Nutrition Act of 1966, Public law 104210/1996, 110 STAT. 3011 (online available at www.law.cornell.edu/uscode/text/42/1791, last access 2016-01-20).

BMLFUW (2008) EU: 26 Vermarktungsnormen bei Obst und Gemüse gestrichen - Krumme Gurken und knollige Karotten künftig erlaubt (EU: 26 marketing standards regarding fruits and vegetables cancelled - in future buckled cucumber and bulbous carrots permitted). (presse.lebensministerium.at/article/articleview/71264/1/21503/, accessed 2011-01-11).

Canali M. [Ed.] (2014) Drivers of current food waste generation, threats of future increase and opportunities for reduction. Report, Bologna, ISBN: 978-94-6257-354-3. (online available at http://www.eu-fusions.org/index.php/download?download=111:drivers-of-current-food-wastegeneration-threats-of-future-increase-and-opportunities-for-reduction, last access 2016-01-19)

Deutsche Wirtschaftsnachrichten (2014) Belgien: Region beschließt Gesetz gegen Verschwendung von Lebensmitteln (Begium: Region determine law against food wastage). Online article, available at http://deutsche-wirtschafts-nachrichten.de/2016/01/20/russland-bereitet-sich-auf-militaerischeeskalation-durch-tuerkei-vor/, last access 2016-01-20.

FUSIONS (2015) FUSIONS Food waste data set for EU-28 - New Estimates and Environmental Impact. Report, online available at http://www.eu-fusions.org/index.php/download?download=177:fusionsfood-waste-data-set, last access 2016-01-20.

Kranert M., Hafner G., Barabosz J., Schneider F., Lebersorger S., Scherhaufer S., Schuller H., Leverenz D. (2012) Determination of discarded food and proposals for a minimization of food wastage in Germany. Abridged Version on behalf of German Federal Ministry of Food, Agriculture and Consumer Protection, Stuttgart, available at http://www.bmel.de/SharedDocs/Downloads/EN/Food/Studie Lebensmittelabfaelle Kurzfassung.pdf? blob=publicationFile, last access 2016-01-20.

La Legge del Buon Samaritano: Legge 25 giugno 2003, n.155, Disciplina della distribuzione dei prodotti alimentari a fini di solidarieta' sociale. 25.07.2003, n.155 (online available at gazzette.comune.jesi.an.it/2003/150/3.htm, last access 2016-01-20).

Lebersorger S., Schneider F. (2014) Aufkommen an Lebensmittelverderb im österreichischen Lebensmittelhandel (Generation of food loss at Austria retail). Report on behalf of ECR Austria, Vienna. (online available at http://www.ecraustria.at/images/ECR/Arbeitsgruppen/Abfallvermeidung/berichte/ECRStudie BOKU Lebensmittelverderb.pdf, last access 2016-01-20)

Lienbacher, E., Holweg, C. (2011) Strukturanalyse Sozialmärkte in Österreich (Structural analysis social supermarkets in Austria). In: Schnedlitz, P. (Ed.), Schriftenreihe Handel und Marketing. Band 74, Vienna.

Matousek A. (2014) Green Packaging Initiative von Ja! Natürlich und Wunderlinge (Green Packaging initiative by Ja! Natürlich and wonky product trade mark "Wunderlinge"). Presentation at ECR-task group Waste Prevention, Vienna, 2014-01-29.

Novotny C. (2011) Auswirkungen der Vermeidung von Lebensmittelabfällen durch sozialen Wertstofftransfer (Impact on food waste prevention through redistribution). Master thesis at BOKU- 
University of Natural Resources and Life Sciences, Vienna, online available at http://www.wau.boku.ac.at/fileadmin/data/H03000/H81000/H81300/IKS_Files/Forschung/Lebensmitte l/Novotny_Masterarbeit_final.pdf, last access 2016-01-20.

Pladerer C., Hietler P., Kalleitner-Huber M., Bernhofer G., Meissner M. (2015) Lebensmittelweitergabe in Österreich: ein aktiver Beitrag zur Abfallvermeidung - IST-Stand und Bedarfserhebung der Lebensmittelweitergabe in sozialen und gemeinnützigen Einrichtungen in Österreich (Food redistribution in Austria: a direct contribution to waste prevention - state of the art and assessment of demand related to food redistribution at charities and non-profit organisation in Austria). Report, Vienna, online available at http://www.ecology.at/ecology/files/berichte/E10.916.pdf, last access 2016-01-20.

Scherhaufer S., Schneider F. (2011) Prevention, Recycling and Disposal of Waste Bread in Austria. In: Cossu, R., He, P., Kjeldsen, P., Matsufuji, Y., Reinhart, D., Stegmann, R., (Eds.). Sardinia 2011 Thirteenth International Waste Management and Landfill Symposium (October 3-7, 2011, S. Margherita di Pula, Sardinia, Italy). Executive Summaries, CISA Environmental Sanitary Engineering Centre. ISBN 978-88-6265-000-7. Abstract, pp. 15-16. (Full paper on CD).

Schmied E. (2003) (Weiter-)Nutzung brauchbarer Produkte als Beitrag zur Abfallvermeidung (Extended use of products as contribution to waste prevention). ). Master thesis at BOKU-University of Natural Resources and Life Sciences, Vienna, online available https://zidapps.boku.ac.at/abstracts/oe_list.php?paID=3\&paCF=0\&paLIST=0\&paSID=4332, last access 2016-01-20.

Schneider F. (2013) The evolution of food donation with respect to waste prevention. Waste Management 33 (2013) 755-763.

Schneider F., Lebersorger S. (2011) Barriers for the implementation of prevention measures concerning food waste. 3rd international Conference "Waste - The Social Context", May 08 - 11, 2011, Edmonton, Alberta.

Schneider F., Lebersorger S., Bernhold H., Zehetgruber B. (2014) Orientierende Erhebung von Verlusten an Obst, Gemüse und Kartoffeln in der Landwirtschaft - Aufkommen, Zusammensetzung und Gründe (Preliminary assessment of losses of fruits, vegetables and potatoes in agriculture Generation, composition and reasons). Final report, on behalf of Austrian Federal Ministry of Agriculture, Forestry, Environment and Water management, Vienna, unpublished.

Schneider, F., Wassermann, G. (2004) Sozialer Wertstofftransfer im Einzelhandel (Social transfer of goods from retail trade). Report, on behalf of Initiative Abfallvermeidung in Wien (Initiative Waste Prevention in Vienna), Vienna.

Vittuari M., Politano A., Gaiani S., Canali M., Elander M. (2015) Review of EU Member States legislation and policies with implications on food waste. Report, Bologna, ISBN: 978-94-6257-525-7. (online available at http://www.eu-fusions.org/index.php/download?download=161:review-of-eu-legislationand-policies-with-implications-on-food-waste, last access 2016-01-20)

Zeit online (2015) Frankreichs Supermärkte dürfen Lebensmittel nicht wegwerfen (Retail markets in France are not allowed to dispose food). Online article, available at http://www.zeit.de/politik/ausland/2015-05/lebensmittel-verschwendung-frankreich, last access 201601-20.

Canali, M. et all (2015) Drivers of current food waste generation, threats of future increase and opportunities for reduction http://eu-fusions.org/index.php/publications

European Commission (2014), Towards a circular economy: a zero waste programme for Europe http://eur-lex.europa.eu/resource.html?uri=cellar:aa88c66d-4553-11e4-a0cb-

01aa75ed71a1.0022.03/DOC_1\&format=PDF

European Commission (2015), Flash Eurobarometer 425 on food waste and date marking, http://ec.europa.eu/COMMFrontOffice/PublicOpinion/index.cfm/Survey/getSurveyDetail/instruments/FL ASH/surveyKy/2095

European Commission (2015), Closing the loop - An EU action plan for the Circular Economy http://ec.europa.eu/environment/circular-economy/index en.htm 
Östergren, $\mathrm{K}$ et all (2014) Report on review of (food) waste reporting methodology and practice http://eu-fusions.org/index.php/publications 


\section{Annex 1. Interviewed experts}

Experts interviewed for the setting Food donation/redistribution in a context of social innovation

\begin{tabular}{|l|l|l|l|}
\hline \multicolumn{1}{|c|}{ Expert } & \multicolumn{1}{|c|}{ Organization } & \multicolumn{1}{|c|}{ Type of organization } & \multicolumn{1}{c|}{ Date } \\
\hline Mark Little & Tesco & Commercial & 28.07 .16 \\
\hline $\begin{array}{l}\text { Lorenzo Ferrucci and } \\
\text { David Bellamy }\end{array}$ & FoodDrinkEurope & European organisation & 15.07 .16 \\
\hline Matteo Guidi & Last Minute Market & NGO (Onlus) & 05.07 .16 \\
\hline $\begin{array}{l}\text { Diogo Lorena and Paula } \\
\text { Policarpo }\end{array}$ & Dariacordar & NGO & 05.07 .16 \\
\hline $\begin{array}{l}\text { Angela Frigo and Marco } \\
\text { Lucchini }\end{array}$ & Banco Alimentare & NGO (Fundation) & 05.07 .16 \\
\hline Patrick Alix & European Federation of Food Banks & European organisation & 05.07 .16 \\
\hline Odile Leboch & Environmental Protection Agency & Governamental agency & 26.07 .16 \\
\hline $\begin{array}{l}\text { Etienne Rubens and Caroo } \\
\text { Torfs }\end{array}$ & Komosie & NGO & 04.07 .16 \\
\hline Alexander Theodoridis & BOROUME & Non-profit organization & 01.07 .16 \\
\hline $\begin{array}{l}\text { Katalin Ujhelyi and Cseh } \\
\text { Balazs }\end{array}$ & HFA & NGO & 23.06 .16 \\
\hline
\end{tabular}

Experts interviewed for the setting Multi-target approach towards reducing food waste

\begin{tabular}{|l|l|l|l|}
\hline \multicolumn{1}{|c|}{ Expert } & \multicolumn{1}{|c|}{ Organization } & \multicolumn{1}{c|}{$\begin{array}{c}\text { Type of } \\
\text { organization }\end{array}$} & \multicolumn{1}{c|}{ Date } \\
\hline Asa Stenmark & IVL & Academia & 01.07 .2016 \\
\hline Karin Ostergren & SP Technical Research Institute of Sweden & Academia & 01.07 .2016 \\
\hline Julian Parfitt & Anthesis & Consultant & 05.07 .2016 \\
\hline David Rogers & WRAP & NGO & 04.07 .2016 \\
\hline Felicitas Schneider & BOKU & Academia & 06.07 .2016 \\
\hline Illaria Passarini & BEUC & European organisation & 05.07 .2016 \\
\hline $\begin{array}{l}\text { Keith Waldron and } \\
\text { Graham Moates }\end{array}$ & Institute of Food Research & Academia & 05.07 .2016 \\
\hline Karen Luyckx & Feedback & NGO & 06.07 .2016 \\
\hline Cecilia Maronnier & Envicient & Consultant & 04.07 .2016 \\
\hline
\end{tabular}

The information and views set out in this report represent the interpretation of the authors and do not necessarily reflect the opinion of the experts engaged in the interviews. 